ARTICLE

\title{
Visualizing the enzyme mechanism of mevalonate diphosphate decarboxylase
}

\author{
Chun-Liang Chen (10 ${ }^{1}$, Lake N. Paul ${ }^{2,3}$, James C. Mermoud ${ }^{1}$, Calvin Nicklaus Steussy ${ }^{1} \&$ \\ Cynthia V. Stauffacher (D) $1,4 \times$
}

Mevalonate diphosphate decarboxylases (MDDs) catalyze the ATP-dependent- $\mathrm{Mg}^{2+}$ decarboxylation of mevalonate-5-diphosphate (MVAPP) to produce isopentenyl diphosphate (IPP), which is essential in both eukaryotes and prokaryotes for polyisoprenoid synthesis. The substrates, MVAPP and ATP, have been shown to bind sequentially to MDD. Here we report crystals in which the enzyme remains active, allowing the visualization of conformational changes in Enterococcus faecalis MDD that describe sequential steps in an induced fit enzymatic reaction. Initial binding of MVAPP modulates the ATP binding pocket with a large loop movement. Upon ATP binding, a phosphate binding loop bends over the active site to recognize ATP and bring the molecules to their catalytically favored configuration. Positioned substrates then can chelate two $\mathrm{Mg}^{2+}$ ions for the two steps of the reaction. Closure of the active site entrance brings a conserved lysine to trigger dissociative phosphoryl transfer of $\gamma$-phosphate from ATP to MVAPP, followed by the production of IPP.

\footnotetext{
1 Department of Biological Sciences, Purdue University, West Lafayette, IN 47907, USA. ${ }^{2}$ BioAnalysis, LLC, 1135 Dunton Street, Unit 2, Philadelphia, PA 19123, USA. ${ }^{3}$ Biophysical Analysis Laboratory, Bindley Bioscience Center, Purdue University, West Lafayette, IN 47906, USA. ${ }^{4}$ Purdue University Center for Cancer Research (PUCCR), Purdue University, West Lafayette, IN 47907, USA. ${ }^{\circledR}$ email: cstauffa@purdue.edu
} 
iving cells produce diverse isoprenoids for maintaining cell integrity. In humans, one example is the synthesis of cholesterol by enzymes in the isoprenoid pathway, as well as to produce essential molecules such as hormones and bile acids. Similarly, microbes produce isoprenoids involved in the respiratory chain and cell wall synthesis ${ }^{1,2}$. Isoprenoids are synthesized from two basic building blocks, dimethylallyl diphosphate (DMAPP) and isopentenyl diphosphate (IPP). These two basic units are the ultimate products from two highly divergent isoprenoid pathways, the methylerythritol 4-phosphate (MEP) pathway found primarily in bacteria and the mevalonate (MVA) pathway found primarily in eukaryotes, although plants typically have both.

The genome sequence explosion revealed an unexpected exception to this rule. In some low GC content Gram $(+)$ cocci, such as staphylococci, streptococci and enterococci, the mevalonate pathway exists and is essential for IPP production and pivotal for bacterial growth ${ }^{3}$. Thus, enzymes in the mevalonate pathway have been suggested as therapeutic targets for treatment of infectious diseases caused by these $\operatorname{Gram}(+)$ bacterial pathogens, especially for those bearing multidrug-resistance genes such as methicillin-resistant Staphylococcus aureus (MRSA) and vancomycin-resistant enterococci $(\mathrm{VRE})^{4-6}$, which cause a range of clinical infections ${ }^{4-8}$. Until now, there have only been a few therapeutic options available for treatment of such bacterial infections and resistance to these treatments is rising ${ }^{9-14}$. Development of antimicrobial agents has therefore become an urgent issue.

In the mevalonate pathway, the mevalonate diphosphate decarboxylase (MDD, EC: 4.1.1.33) is a rate-limiting enzyme ${ }^{15}$, suggesting that inhibition of MDD could eliminate the products of the mevalonate pathway and accordingly shut down bacterial growth. In addition, an in vitro study had shown feedback regulation by mevalonate-5-diphosphate (MVAPP) of the mevalonate kinase (MK) from Streptococcus pneumonia ${ }^{16}$. This implies that accumulation of MVAPP caused by inhibition of MDD can down-regulate the upstream MK enzymes, also indicating that the mevalonate pathway can be effectively inhibited by targeting the MDD enzyme. A broad-spectrum substrate-mimicking inhibitor

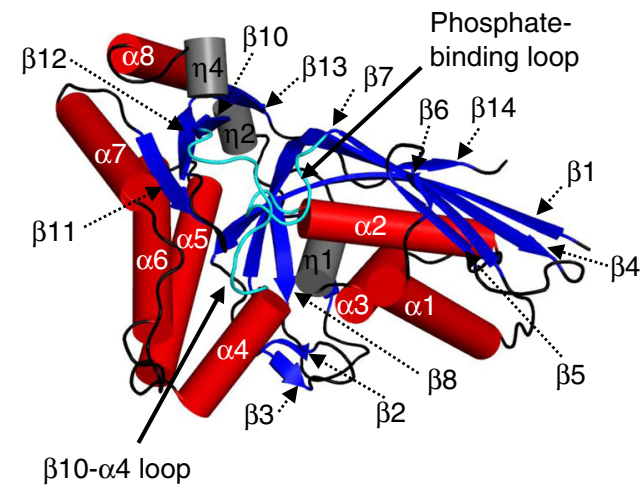

Fig. $1 \mathbf{M D D}_{\mathrm{EF}}$ structure. The crystal structure of $M D D_{E F}$ in complex with MVAPP, $\mathrm{ADPBeF}_{3}$, and $\mathrm{Mg}^{2+}\left(\mathrm{MDD}_{\mathrm{EF}}-\mathrm{MVAPP}-\mathrm{ADPBeF}_{3}-\mathrm{Mg}^{2+}\right)$ was analyzed by PROMOTIF ${ }^{61}$. Secondary structure elements, $\alpha$-helices (red cylinders), 310 -helices (gray cylinders) and $\beta$-sheets (blue arrows) are drawn and labeled as $\alpha, \eta$, and $\beta$. The $\beta 10-\alpha 4$ loop and the phosphatebinding loop are shown in cyan. The range of amino acid numbers of each secondary structural element is listed as following: $\beta 1(1-15), \beta 2(20-22), \beta 3$ $(27-28), \beta 4(32-49), \beta 5(56-59), \beta 6(62-63), \beta 7(89-96), \beta 8(149-153), \beta 9$ (162-165), $\beta 10(175-180), \beta 11(277-280), \beta 12(287-292), \beta 13(312-315), \beta 14$ (322-324), $\alpha 1(66-81), \alpha 2(105-120), \alpha 3(127-137), \alpha 4(191-201), \alpha 5$ (205-224), $\alpha 6(228-246), \alpha 7(258-272), \alpha 8(298-303), \eta 1(139-142), \eta 2$ (171-174), $\eta 3(293-297), \eta 4(308-311)$. of MDD, 6-fluoromevalonate diphosphate (FMVAPP), has been identified. This inhibitor, however, binds to the highly conserved MVAPP-binding site in the MDD family of proteins (MDDs) ${ }^{17-22}$, including human MDD. To avoid side effects on humans when treating bacterial infections, structure-based drug development toward an MDD with both sensitivity and specificity is needed ${ }^{23}$.

MDDs perform a sequential ordered bi-substrate mechanism with MVAPP as the first substrate $17,24,25$ followed by ATP binding. The $\gamma$-phosphate group of ATP is transferred to MVAPP to make the $3^{\prime}$-phosphate-MVAPP intermediate, which is then subjected to dephosphorylation and decarboxylation to produce IPP. Although it was proposed that the ATP-dependent decarboxylation of MVAPP ${ }^{26}$ might be initiated via deprotonation of $3^{\prime}-\mathrm{OH}$ of MVAPP by a conserved aspartic acid (D282 in MDD from Enterococcus faecalis, and D283 in MDD from Staphylococcus epidermidis), followed by the transfer of the $\gamma$-phosphate of ATP to $\mathrm{MVAPP}^{27}$, recent mutagenesis studies on MDD from Sulfolobus solfataricus $\left(\mathrm{MDD}_{\mathrm{SS}}\right)$ have demonstrated that the catalytic Asp residue may function in dephosphorylation and decarboxylation of the $3^{\prime}$-phosphate-MVAPP intermediate, rather than deprotonation of the $3^{\prime}-\mathrm{OH}$ group of $\mathrm{MVAPP}^{28}$. However, the phosphoryl transfer efficiencies of the D281T or D281V mutants of $\mathrm{MDD}_{\mathrm{SS}}$ are lower than the wild-type $\mathrm{MDD}_{\mathrm{SS}}$, implying some involvement of the Asp in this step.

In addition, although the reaction requires magnesium ions for catalysis $^{17,18,29}$, no metal ions have been found in previously published MDD structures ${ }^{17,18}$. This indicates that current structural models of MDDs may not provide sufficient information for elucidating the enzyme mechanism or designing effective inhibitors of MDDs.

In this study, we utilized MDD from Enterococcus faecalis V583 $\left(\mathrm{MDD}_{\mathrm{EF}}\right)$, a VRE strain, and investigated the enzyme from structural, functional and biophysical points of view. Our present results suggest that the substrate-binding mechanism of MDDs involves programmed conformational rearrangements in and around the active site, including movements of the $\beta 10-\alpha 4$ loop, the phosphate-binding loop, and three helices, $\alpha 1, \alpha 2$, and $\alpha 4$. In the analysis of these conformational changes, the critical role of a conserved lysine (K187) in catalysis also became clear. These findings provide insight into a detailed MDD enzyme mechanism, which then can shed light on specific drug development against the MDD proteins of drug-resistant pathogenic bacteria $^{5,7,9,10,22,30,31}$.

\section{Results}

Analysis of $\mathrm{MDD}_{\mathrm{EF}}$ crystal structures in reaction steps. The investigation of the structural details of the $\mathrm{MDD}_{\mathrm{EF}}$ mechanism was aided by the discovery of crystallization conditions under which the introduction of substrates and cofactors by soaking resulted in activity in the crystal. These $\mathrm{MDD}_{\mathrm{EF}}$ crystals were grown at a high ammonium sulfate concentration $(1.6 \mathrm{M})^{19}$ but subjected to buffer exchange into PEG3350 solutions before soaking with ligands. In this study, crystal structures of apo

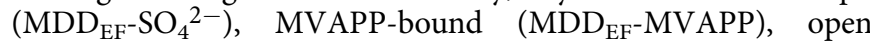
$\left(\mathrm{MDD}_{\mathrm{EF}}-\mathrm{MVAPP}-\mathrm{AMPPCP}-\mathrm{Mg}^{2+}\right)$, and closed conformations of $\mathrm{MDD}_{\mathrm{EF}}\left(\mathrm{MDD}_{\mathrm{EF}}-\mathrm{MVAPP}-\mathrm{ADPBeF}_{3}-\mathrm{Mg}^{2+}\right.$ and $\mathrm{MDD}_{\mathrm{EF}^{-}}$ MVAPP-ADP-SO ${ }_{4}^{2-}-\mathrm{Co}^{2+}$ ) were obtained by providing the apo enzyme crystals with the appropriate sets of substrates. A nearly full-length (residue 1-326) structural model was generated from

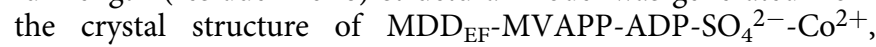
showing that $\mathrm{MDD}_{\mathrm{EF}}$ folds into a two-layer sandwich architecture with $\alpha$ and $\beta$ secondary structure elements ( $\alpha \beta$ class) (Fig. 1), similar to those for published MDD structures. Information 
Table 1 Data collection and refinement statistics.

\begin{tabular}{|c|c|c|c|c|c|c|}
\hline & $\begin{array}{l}\mathrm{MDD}_{\mathrm{EF}^{-}} \\
\mathrm{SO}_{4}^{2-} \\
\end{array}$ & $\begin{array}{l}\text { MDD }_{\mathrm{EF}^{-}} \\
\text {MVAPP }\end{array}$ & $\begin{array}{l}\text { MDD }_{\mathrm{EF}-\mathrm{MVAPP}} \\
\text { AMPPCP-Mg}^{2+}\end{array}$ & $\begin{array}{l}\text { MDD }_{\mathrm{EF}-\mathrm{MVAPP}} \\
\mathrm{ADPBeF}_{\mathbf{3}}-\mathrm{Mg}^{2+}\end{array}$ & 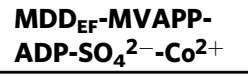 & $\begin{array}{l}\text { MDD }_{\mathrm{EF}}-\mathrm{MVAPP}- \\
\mathrm{ADP}_{-\mathrm{SO}_{\mathbf{4}}{ }^{2-}-\mathrm{Co}^{2+}}\end{array}$ \\
\hline \multicolumn{7}{|l|}{ Data collection } \\
\hline Space group & $P 2{ }_{1} 2_{1} 2$ & $P 2{ }_{1} 2_{1} 2$ & $P 2{ }_{1}{ }_{1} 2$ & $P 2{ }_{1}{ }_{1} 2$ & $P 2{ }_{1} 2_{1} 2$ & $P 2_{1} 2_{1} 2$ \\
\hline \multicolumn{7}{|l|}{ Cell dimensions } \\
\hline$a, b, c(\AA)$ & $82.4,97.9,45.7$ & $\begin{array}{l}\text { 79.3, } \\
97.4,45.8\end{array}$ & $80.0,97.0,46.0$ & $79.6,98.6,45.6$ & $80.0,98.1,45.9$ & $79.9,98.0,45.9$ \\
\hline$\alpha, \beta, \gamma\left({ }^{\circ}\right)$ & $90,90,90$ & $90,90,90$ & $90,90,90$ & $90,90,90$ & $90,90,90$ & $90,90,90$ \\
\hline Resolution $(\AA)^{a}$ & $\begin{array}{l}50-1.8 \\
(1.86-1.80)\end{array}$ & $\begin{array}{l}50-1.7 \\
(1.76-1.70)\end{array}$ & $30-2.1(2.12-2.05)$ & $30-2.1(2.18-2.10)$ & $50-2.0(2.02-1.95)$ & $30-2.4(2.43-2.35)$ \\
\hline$R_{\text {merge }}$ & $6.1(50.1)$ & $5.0(43.8)$ & $4.1(51.3)$ & $5.8(52.3)$ & $5.4(48.9)$ & $7.7(49.5)$ \\
\hline$|/ \sigma|$ & $32.3(3.1)$ & $40.3(4.1)$ & $38.6(2.5)$ & $23.3(2.2)$ & $37.8(3.5)$ & $40.0(4.5)$ \\
\hline $\mathrm{CC}_{1 / 2}$ & $0.980(0.926)$ & $0.982(0.931)$ & $0.964(0.846)$ & $0.954(0.832)$ & $0.980(0.917)$ & $0.984(0.920)$ \\
\hline Completeness (\%) & $99.2(100)$ & 99.5 (100) & $96.6(98.5)$ & $99.8(99.8)$ & $99.2(100)$ & 99.5 (99.9) \\
\hline Redundancy & $7.0(6.9)$ & $6.8(6.8)$ & $5.1(4.9)$ & $4.5(4.0)$ & $6.8(6.7)$ & $12.7(12.3)$ \\
\hline \multicolumn{7}{|l|}{ Refinement } \\
\hline Resolution $(\AA)$ & $30-1.8$ & $30-1.7$ & $30-2.0$ & $30-2.1$ & $34-2.0$ & $27-2.3$ \\
\hline No. of reflections & 34,579 & 39,789 & 22,148 & 21,068 & 26,418 & 15,594 \\
\hline$R_{\text {work }} / R_{\text {free }}$ & $0.186 / 0.211$ & $0.153 / 0.175$ & $0.193 / 0.217$ & $0.173 / 0.192$ & $0.196 / 0.219$ & $0.183 / 0.222$ \\
\hline \multicolumn{7}{|l|}{ No. of atoms } \\
\hline Protein & 2607 & 2487 & 2528 & 2528 & 2528 & 2528 \\
\hline Ligand/ion & 10 & 18 & 50 & 51 & 52 & 52 \\
\hline Water & 234 & 382 & 91 & 146 & 187 & 187 \\
\hline \multicolumn{7}{|l|}{$B$-factors } \\
\hline Protein & 23.3 & 15.7 & 31.1 & 27.4 & 27.6 & 34.5 \\
\hline Ligand/ion & 28.6 & 10.2 & 34.1 & 22.0 & 20.8 & 30.9 \\
\hline Water & 31.5 & 27.4 & 30.9 & 29.6 & 29.8 & 35.8 \\
\hline \multicolumn{7}{|l|}{ R.m.s. deviations } \\
\hline Bond lengths $(\AA)$ & 0.005 & 0.006 & 0.01 & 0.012 & 0.01 & 0.01 \\
\hline Bond angles $\left(^{\circ}\right)$ & 0.78 & 1.02 & 1.02 & 1.13 & 1.00 & 1.00 \\
\hline PDB code & $6 \mathrm{E} 2 \mathrm{~S}$ & $6 \mathrm{E} 2 \mathrm{~T}$ & $6 E 2 U^{b}$ & $6 \mathrm{E} 2 \mathrm{~V}$ & 6E2W & $6 E 2 Y^{b}$ \\
\hline
\end{tabular}

regarding data collection and refinement statistics is summarized in Table 1.

The apo form of $\mathrm{MDD}_{\mathrm{EF}}\left(\mathrm{MDD}_{\mathrm{EF}^{-}} \mathrm{SO}_{4}{ }^{2-}\right)$ has almost identical secondary structure elements compared with other MDDs. However, the phosphate-binding loop (97-104) and the $\beta 10-\alpha 4$ loop (183-190) cannot be determined in this apo structure, which is different from other published apo-MDD structures ${ }^{17,19,32}$ (Supplementary Table 1). Compared with them, no crystalpacking contacts were found in these two loop regions of the apo$\mathrm{MDD}_{\mathrm{EF}}$ presented here, implying that these two loops may be dynamic or disordered in the structure. In the $\mathrm{MDD}_{\mathrm{EF}}-\mathrm{MVAPP}$ structure, the conformation of the $\beta 10-\alpha 4$ loop (Fig. 2a) and MVAPP can now be clearly seen (Fig. 2b). Although the binding configuration of MVAPP and the $\beta 10-\alpha 4$ loop are similar to what had been determined in other published MVAPP-bound MDD structures $^{18}$, the $\beta 10-\alpha 4$ loop appears to be stabilized by helix $\alpha 4$, which interacts with MVAPP through the bonds between the pyrophosphate of MVAPP and the residues S191 and R192 of helix $\alpha 4$. These interactions may confine the preceding $\beta 10-\alpha 4$ loop to a certain configuration and accomplish the first step in the reaction.

To investigate any structural rearrangements upon ATP binding in the next reaction step, $\mathrm{MDD}_{\mathrm{EF}^{-}}-\mathrm{MVAPP}$ crystals were soaked with ATP analogs (AMPCP or $\mathrm{ADPBeF}_{3}$ ) to mimic two substrate-bound $\mathrm{MDD}_{\mathrm{EF}}$ structures before ATP cleavage and in the transition step. This resulted in two different conformationsopen $\left(\mathrm{MDD}_{\mathrm{EF}^{-}}-\mathrm{MVAPP}-\mathrm{AMPPCP}-\mathrm{Mg}^{2+}\right)$ and closed $\left(\mathrm{MDD}_{\mathrm{EF}^{-}}\right.$ MVAPP-ADPBeF $3-\mathrm{Mg}^{2+}$ ) conformations of $\mathrm{MDD}_{\mathrm{EF}}$ (Fig. 2c-f). In the open conformation, the $\beta 10-\alpha 4$ loop and the phosphatebinding loop are now ordered in the active site (Fig. 2c), as are the ligands, MVAPP and ATP/AMPPCP (Fig. 2d). This suggested that the MgATP binding can trigger conformational changes of the phosphate-binding loop to take up a position poised over the active site but still open. This configuration was also observed in our previously published $\mathrm{MDD}_{\mathrm{EF}^{-}}$ATP structure (5V2L) ${ }^{24}$. Note that these two loops do not directly contact active site ligands in the open $\mathrm{MDD}_{\mathrm{EF}}$ conformation, suggesting that substrate binding may reshape the general active site environment and stabilize helices $\alpha 2$ and $\alpha 4$, which leads to overall stabilization of the phosphate-binding loop and the $\beta 10-\alpha 4$ loop, respectively. Interestingly, an extra density not explained by MVAPP or AMPPCP appears to be between the phosphate groups of substrates. This density is surrounded by five oxygen atoms (one from MVAPP, three from AMPPCP and one from $\gamma-\mathrm{OH}$ of S106), implicating that the extra electron density is a magnesium ion (Fig. 2d).

In the closed conformation of $\mathrm{MDD}_{\mathrm{EF}}\left(\mathrm{MDD}_{\mathrm{EF}}-\mathrm{MVAPP}\right.$ $\mathrm{ADPBeF}_{3}-\mathrm{Mg}^{2+}$ ) (Fig. $2 \mathrm{e}, \mathrm{f}$ ), the $\beta 10-\alpha 4$ loop and the phosphatebinding loop have become close around the active site entrance. Ligand densities in the active site were clearly distinguishable (Fig. 2f). In this structure, not one but two extra spherical densities not belonging to MVAPP or $\mathrm{ADPBeF}_{3}$ were identified. One spherical density is surrounded by six oxygen atoms (one from MVAPP, two from $\mathrm{ADPBeF}_{3}$, one from the $\gamma-\mathrm{OH}$ of $\mathrm{S} 106$ and one from water), and the other one is coordinated by five oxygen atoms (three from water and two from MVAPP) and one fluorine atom from $\mathrm{BeF}_{3}{ }^{-}$. These two spherical densities are suggested to be the magnesium ions required for the MDD reaction (Fig. 2f). Two metal-binding sites were later confirmed with a distinct anomalous signal of cobalt ions in the complex 
a

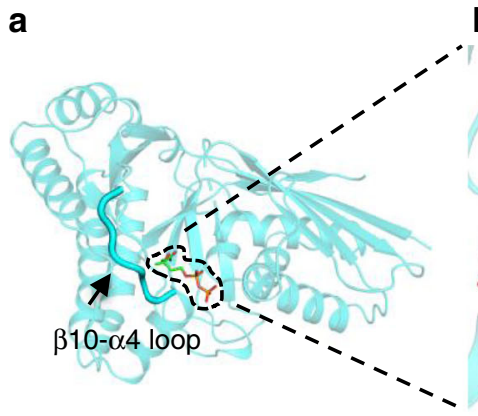

c d

b
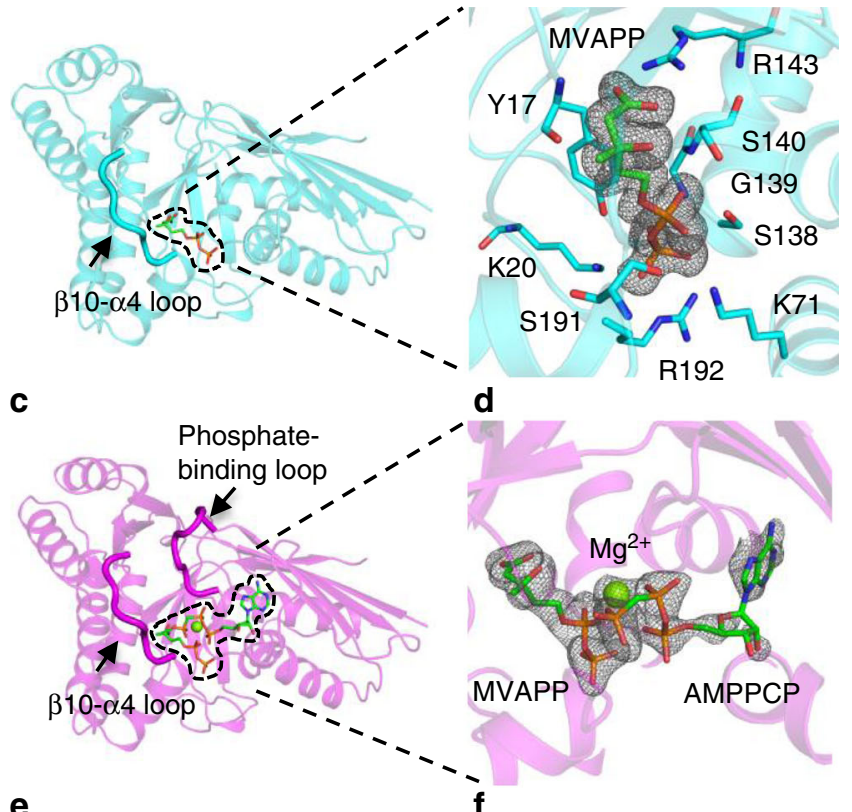

e

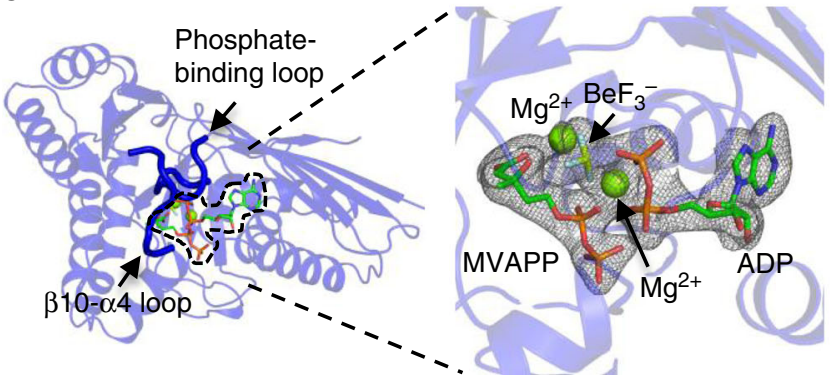

Fig. 2 Structural models of bound forms of $\mathbf{M D D}_{\mathrm{EF}}$. a Structural model of $\mathrm{MDD}_{\mathrm{EF}}-\mathrm{MVAPP}$. The $\beta 10-\alpha 4$ loop is indicated by a black arrow. b SAligand-omit map of MVAPP of MDD $\mathrm{EF}_{\mathrm{EF}} \mathrm{MVAPP}$. The map is presented at a sigma level of three $(3 \sigma)$. MVAPP and the interacting residues in the active site of $M D D_{E F}$ are shown as stick models. c Structural model of $\mathrm{MDD}_{\mathrm{EF}^{-}}$ MVAPP-AMPPCP- $\mathrm{Mg}^{2+}$. The $\beta 10-\alpha 4$ loop and the phosphate-binding loop are indicated by black arrows. d SA-omit map $(3 \sigma)$ of ligands of $\mathrm{MDD}_{\mathrm{EF}^{-}}$ MVAPP-AMPPCP-Mg ${ }^{2+}$. e Structural model of the MDD EF-MVAPP$\mathrm{ADPBeF}_{3}-\mathrm{Mg}^{2+}$. The $\beta 10-\alpha 4$ loop and the phosphate-binding loop are indicated by black arrows. f SA-omit map $(3 \sigma)$ of ligands in $\mathrm{MDD}_{\mathrm{EF}}{ }^{-}$ MVAPP-ADPBeF $3-\mathrm{Mg}^{2+}$. Ligand-binding sites in $\mathbf{a}, \mathbf{c}$, and $\mathbf{e}$ are indicated by dashed lines.

structure of $\mathrm{MDD}_{\mathrm{EF}}-\mathrm{MVAPP}-\mathrm{ADP}-\mathrm{SO}_{4}{ }^{2-}{ }_{-} \mathrm{Co}^{2+}$ (described in the next section).

$\mathrm{ADPBeF}_{3}$ is an ATP analog in which $\mathrm{BeF}_{3}{ }^{-}$mimics the $\gamma$ phosphoryl group of $\mathrm{ATP}^{33}$. In $\mathrm{MDD}_{\mathrm{EF}}-\mathrm{MVAPP}-\mathrm{ADPBeF}_{3}-$ $\mathrm{Mg}^{2+}, \mathrm{BeF}_{3}{ }^{-}$was located between the $\mathrm{O} \beta$ atom of ADP and 3'oxygen of MVAPP, and the angle of $\mathrm{O} \beta-\mathrm{Be}-3^{\prime}-\mathrm{O}$ was determined to be nearly $180^{\circ}\left(178^{\circ}\right)$, suggesting that the $\mathrm{BeF}_{3}$ molecule is located in an in-line phosphoryl transfer position. The distance of the $3^{\prime}$-oxygen of MVAPP to the beryllium atom was determined to be $3.7 \AA$, within a possible phosphate transfer distance (Supplementary Fig. 1). The distance of $\mathrm{O} \beta$ to beryllium is 2.0 $\AA$ (Supplementary Fig. 1), which is longer than a normal $\mathrm{P}-\mathrm{O}$ single bond of $1.6 \AA$, suggesting that $\mathrm{ADPBeF}_{3}$ in our closed complex structure of $\mathrm{MDD}_{\mathrm{EF}}-\mathrm{MVAPP}-\mathrm{ADPBeF}_{3}-\mathrm{Mg}^{2+}$ is situated in a pre-phosphoryl transfer state. The closed $\mathrm{MDD}_{\mathrm{EF}}$ structure represents the state just as the enzymatic transfer begins, whereas the complex structure of $\mathrm{MDD}_{\mathrm{EF}}-\mathrm{MVAPP}-\mathrm{AMPPCP}$ $\mathrm{Mg}^{2+}$ might represent an earlier state upon ATP binding.
The closed conformation of $\mathrm{MDD}_{\mathrm{EF}}$ may restrict bulk water diffusing into the active site to prevent wasteful phosphoryl transfer $^{34}$ during the MDD enzymatic reaction, whereas the active site in $\mathrm{MDD}_{\mathrm{EF}}-\mathrm{MVAPP}-\mathrm{AMPPCP}-\mathrm{Mg}^{2+}$ is still accessible to solvent. In addition, the distance between $3^{\prime}$-oxygen of MVAPP and P $\gamma$ of AMPPCP (6.1 $\AA$ ) is substantially longer than the distance between $3^{\prime}$-oxygen of MVAPP and Be of $\mathrm{ADPBeF}_{3}$ in $\mathrm{MDD}_{\mathrm{EF}}-\mathrm{MVAPP}-\mathrm{ADPBeF} \mathrm{F}_{3}-\mathrm{Mg}^{2+} \quad(3.7 \AA)$. These differences suggest that phosphoryl transfer is unlikely to take place in the open conformation of $\mathrm{MDD}_{\mathrm{EF}}$ as shown in $\mathrm{MDD}_{\mathrm{EF}}$-MVAPPAMPPCP- $\mathrm{Mg}^{2+}$. The occupancy of AMPPCP in the open $\mathrm{MDD}_{\mathrm{EF}}$ structure was about $70 \%$ of that of the closed structure where the occupancy of $\mathrm{ADPBeF}_{3}$ is $100 \%$ and $\mathrm{AMPPCP}$ showed fewer contacts with $\mathrm{MDD}_{\mathrm{EF}}$. A large $K_{\mathrm{IAMPPCP}}$ value $(>1 \mathrm{mM})$ determined from the previous kinetic studies on chicken MDD also supports these observations ${ }^{25}$. This implies that the binding affinity of ATP to the open conformation of $\mathrm{MDD}_{\mathrm{EF}}$ may be initially weak and the active site has to be rearranged for accommodation of this substrate.

Two metal-binding sites in the closed $\mathrm{MDD}_{\mathrm{EF}}$-ligand structure. In the closed conformation of $\mathrm{MDD}_{\mathrm{EF}}-\mathrm{MVAPP}-\mathrm{ADPBeF}_{3}-\mathrm{Mg}^{2+}$, the two extra spherical densities observed were proposed to be two magnesium ions, using the evidence of the coordination by surrounding atoms. However, magnesium does not produce a detectable anomalous signal for identification and its electron density cannot be easily distinguished from a water molecule. In order to confirm whether there are two metal-binding sites formed during the MDD enzymatic reaction, we prepared ligandbound $\mathrm{MDD}_{\mathrm{EF}}$ crystals under buffer conditions with cobalt substituting for magnesium. Cobalt has been confirmed as an alternative cofactor for MDD protein catalysis ${ }^{35}$, and ordered cobalt ions in a crystal lattice can produce a detectable anomalous signal even with a home-source X-ray radiation ${ }^{36}$. To confirm the previous conclusion that cobalt can substitute for magnesium in the buffer condition, enzymatic experiments were conducted and the kinetic parameters of $\mathrm{MDD}_{\mathrm{EF}}$ were determined with cobalt $\left(V_{\max }=9.5 \pm 0.3 \mu \mathrm{Mol} \mathrm{min}^{-1} \mathrm{mg}^{-1}, K_{\mathrm{mMgATP}}=188 \pm 13 \mu \mathrm{M}\right.$, $\left.K_{\text {mMVAPP }}=39.3 \pm 4.0 \mu \mathrm{M}\right)$ (Supplementary Fig. $2 \mathrm{a}$, b and Supplementary Table 2). The $V_{\max }$ value is $\sim 70 \%$ compared with the $V_{\max }$ value under conditions with magnesium, consistent with the previously published results ${ }^{35}$. A decrease in $\mathrm{MDD}_{\mathrm{EF}}$ enzymatic activity is not due to a reduced enzymatic activity of pyruvate kinase in the coupled reaction assay since the assay can detect a reaction rate of $85.4 \pm 1.6 \mu \mathrm{Mol} \mathrm{min}{ }^{-1} \mathrm{mg}^{-1}$ under the conditions with cobalt (Supplementary Fig. 2c).

The anomalous diffraction data for the $\mathrm{MDD}_{\mathrm{EF}}$ bound to MVAPP, ADP, $\mathrm{SO}_{4}{ }^{2-}$, and cobalt (MDD $\mathrm{EF}_{\mathrm{EF}}$-MVAPP-ADP$\left.\mathrm{SO}_{4}{ }^{2-}-\mathrm{Co}^{2+}\right)$ were collected locally with $\mathrm{CuKa} \mathrm{X}$-ray radiation; a higher-resolution diffraction data set from the same crystal was also collected for model building (Table 1and Fig. 3a). The overall structure, the phosphate-binding loop, the $\beta 10-\alpha 4$ loop (Fig. 3a) and ligands in the active site were all well determined in the high resolution map (Fig. 3b, SA-ligand-omit map at $3 \sigma$ ), as were the two spherical electron densities located between MVAPP and ADP-SO ${ }_{4}^{2-}$ suggested to belong to cobalt (Fig. 3b). This 2.0- $\AA$ model was then used to provide phases for the anomalous dispersion data. The resulting anomalous difference map also shows two strong and distinct cobalt positions from the anomalous signal located exactly at the two suggested metalbinding sites (Fig. 3c, anomalous difference map at $5 \sigma$ ).

The crystal structures of $\mathrm{MDD}_{\mathrm{EF}}-\mathrm{MVAPP}-\mathrm{ADPBeF}_{3}-\mathrm{Mg}^{2+}$ and $\mathrm{MDD}_{\mathrm{EF}}-\mathrm{MVAPP}-\mathrm{ADP}-\mathrm{SO}_{4}{ }^{2-}-\mathrm{Co}^{2+}$ were superimposed and analyzed (Supplementary Fig. 3a, b). Although the $\mathrm{Mg}^{2+}$ and $\mathrm{Co}^{2+}$ ions near D282 were located at slightly different positions 

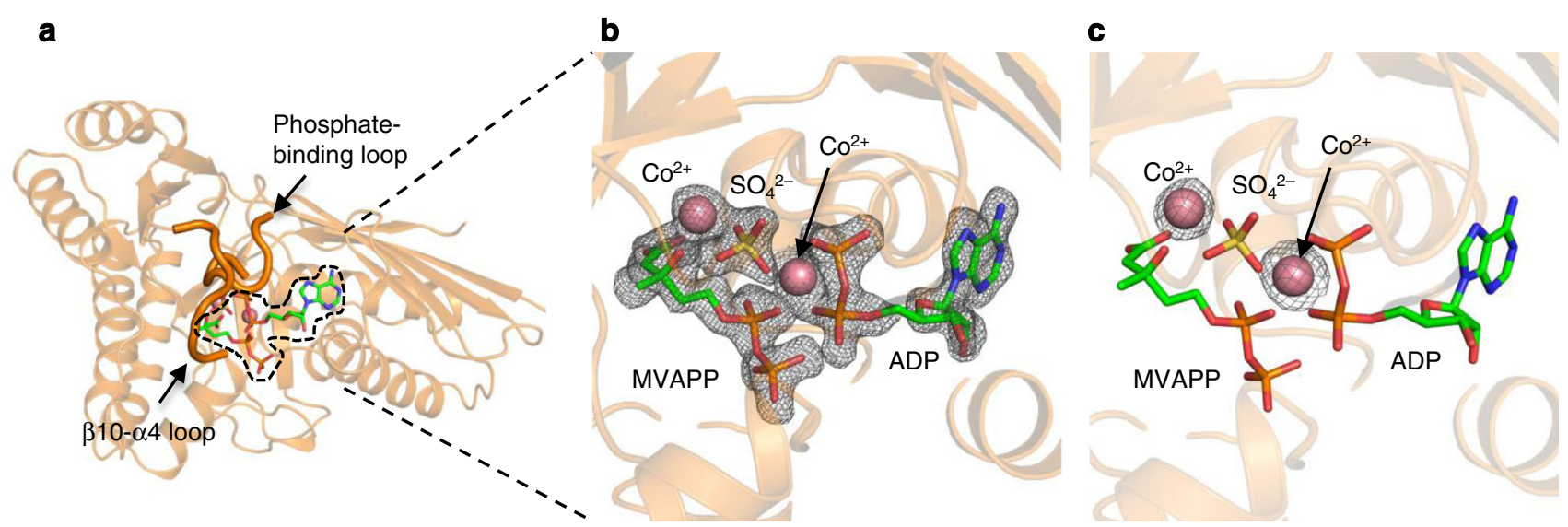

Fig. 3 The two metal-binding sites of $\mathbf{M D D}_{\mathbf{E F}}$ a Structural model of $\mathrm{MDD}_{\mathrm{EF}}-\mathrm{MVAPP}-\mathrm{ADP}-\mathrm{SO}_{4}{ }^{2-}-\mathrm{CO}^{2+}$. The $\beta 10-\alpha 4$ loop and the phosphate-binding loop

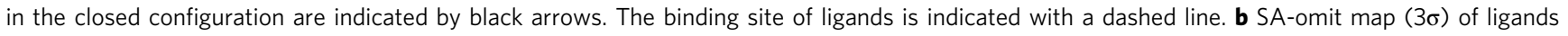
(MVAPP, ADP, $\mathrm{SO}_{4}{ }^{2-}$ and $\mathrm{Co}^{2+}$ ). c An anomalous difference map was derived from the home-source (CuK $\alpha$ ) data set. The anomalous difference map is contoured at a sigma level of five $(5 \sigma)$.

(Supplementary Fig. 3b), this could be due to the slight dislocation of the sulfate ion that experiences steric pressure and charge repulsion from the diphosphate group of ADP. In summary, $\mathrm{MDD}_{\mathrm{EF}}-\mathrm{MVAPP}-\mathrm{ADP}-\mathrm{SO}_{4}{ }^{2-}-\mathrm{Co}^{2+}$ has two cobalt ions in the active site, which are located at similar positions as two spherical densities in $\mathrm{MDD}_{\mathrm{EF}}-\mathrm{MVAPP}-\mathrm{ADPBeF}_{3}-\mathrm{Mg}^{2+}$, suggesting that two magnesium ions are chelated in the active site during the enzymatic reaction. A signal for the metals was only observed in the crystal structures of $\mathrm{MDD}_{\mathrm{EF}^{-}}$ MVAPP-ADP-SO ${ }_{4}^{2-}-\mathrm{Co}^{2+}$ and $\mathrm{MDD}_{\mathrm{EF}}-\mathrm{MVAPP}-\mathrm{ADPBeF}_{3}-$ $\mathrm{Mg}^{2+}$ but not in either apo-MDD $\mathrm{EF}_{\mathrm{EF}}$ or MVAPP-bound $\mathrm{MDD}_{\mathrm{EF}}$ structures, suggesting that two metal-binding sites are transiently formed only in the closed conformation of the $\mathrm{MDD}_{\mathrm{EF}}$-ligand complex.

Dynamic changes of $\mathrm{MDD}_{\mathrm{EF}}$ upon substrate binding. Four different states have been identified in the $\mathrm{MDD}_{\mathrm{EF}}$ enzymatic reaction-an apo form $\left(\mathrm{MDD}_{\mathrm{EF}}-\mathrm{SO}_{4}{ }^{2+}\right)$, a first substrate-bound structure (MDD $\left.\mathrm{EF}_{\mathrm{EF}} \mathrm{MVAPP}\right)$, an open complex structure mimicking a two substrate-bound intermediate ( $\mathrm{MDD}_{\mathrm{EF}}-\mathrm{MVAPP}-$ AMPPCP- $\mathrm{Mg}^{2+}$ ), and a closed complex structure just before the catalytic transition $\left(\mathrm{MDD}_{\mathrm{EF}}-\mathrm{MVAPP}-\mathrm{ADPBeF}_{3}-\mathrm{Mg}^{2+}\right)$. Structural analysis of these $\mathrm{MDD}_{\mathrm{EF}}$ crystal structures revealed dynamics of five regions upon substrate/ligand binding: the phosphate-binding loop, the $\beta 10-\alpha 4$ loop, and three helices that border the active site, $\alpha 1, \alpha 2$, and $\alpha 4$.

The phosphate-binding loop and the $\beta 10-\alpha 4$ loop were observable both in the ligand-bound open $\left(\mathrm{MDD}_{\mathrm{EF}}-\mathrm{MVAPP}\right.$ AMPPCP- $\mathrm{Mg}^{2+}$ ) and closed conformations (MDD $\mathrm{EF}^{-M V A P P-}$ $\mathrm{ADPBeF}-\mathrm{Mg}^{2+}$ ) of $\mathrm{MDD}_{\mathrm{EF}}$ (Fig. 4a). In the open structure, these two loops do not interact with ligands, whereas in the closed conformation of $\mathrm{MDD}_{\mathrm{EF}}$, two loops enclose the active site and form contacts with ligands (Supplementary Table 3). A 9.4- $\AA$ distance change in the $\beta 10-\alpha 4$ loops and a $10.6-\AA \AA$ distance change in the phosphate-binding loops (Fig. 4a) were observed between these two steps. A whole-structure analysis of $\mathrm{Ca}$ positions between the open and closed conformations is shown in Fig. 4b, indicating significant structural changes in these two loop regions.

Key interactions between $\mathrm{MDD}_{\mathrm{EF}}$ and ligands in the three ligand-bound structures are summarized in Supplementary Table 3. Residues in $\alpha 1, \alpha 2$, and $\alpha 4$ interact with ligands differently in these ligand-bound structures of $\mathrm{MDD}_{\mathrm{EF}}$. The gain or loss of $\mathrm{MDD}_{\mathrm{EF}}$-ligand interactions indicates that the three helices, $\alpha 1, \alpha 2$, and $\alpha 4$, move to accommodate substrates during the enzymatic reaction. Figure $5 \mathrm{a}$ shows the positions of helix $\alpha 1$ (left), helix $\alpha 2$ (middle), and helix $a 4$ (right). Figure 5b-d shows the individual positions of helix $\alpha 1$ (Fig. 5b), helix $\alpha 2$ (Fig. 5c), and helix a4 (Fig. 5d) in the four structures, $\mathrm{MDD}_{\mathrm{EF}}-\mathrm{SO}_{4}{ }^{2-}$ (left, representing "State I"), $\mathrm{MDD}_{\mathrm{EF}}$-MVAPP (middle-left, representing "State II"), $\mathrm{MDD}_{\mathrm{EF}}-\mathrm{MVAPP}-\mathrm{AMPPCP}-\mathrm{Mg}^{2+}$ (middle-right,

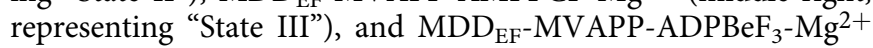
(right, representing "State IV"). By superimposing these four crystal structures, movements of key residues/helical centers in helix a1 (Fig. 5d, left), helix a2 (Fig. 5d, middle), and helix a4 (Fig. 5d, right) upon substrate binding were proposed and are described below.

Q68 and K71 in helix $\alpha 1$ interact with MVAPP and the ATP analogs. Upon MVAPP binding, K71 interacts with the pyrophosphate group of MVAPP, which is consistent with the movement of $\alpha 1$ from state I to state II (Fig. 5b). The movement of al accordingly relocated Q68 to remodel a better ATPbinding pocket, agreeing with our previous results ${ }^{24}$. Although these two residues had been known to form contacts with substrates ${ }^{18}$, the structural dynamics of $\mathrm{MDD}_{\mathrm{EF}}$ helix $\alpha 1$ upon substrate binding is now observed in these structures (Fig. 5b, state I and state II). In higher organisms (e.g., MDD from Arabidopsis thaliana), the Lys residue in helix $\alpha 1$ is replaced with Arg for the interaction with MVAPP ${ }^{37}$, similar to R192 in $\mathrm{MDD}_{\mathrm{EF}}$. Such evolutionary convergence may still facilitate the movement of helix al of MDDs from higher organisms upon MVAPP binding.

Helix a 2 moves towards the active site in an ordered manner when binding to the substrates (Fig. 5c). The movement of helix a2 upon MVAPP binding was unexpected since no direct contact was found between helix $\alpha 2$ and MVAPP. Helix $\alpha 1$ is close to helix $\alpha 2$, so the movement of $\alpha 1$ could affect $\alpha 2$ in order to facilitate the subsequent binding of ATP. A conserved S106 (S107 in $\mathrm{MDD}_{\mathrm{SE}}$ ) in the $\mathrm{N}$ terminus of helix $a 2$ is also positioned differently in these four structures, with a change in side-chain orientation (Fig. $5 c$, e, middle). The role of this conserved serine was previously assigned as a key residue for the binding of the ATP $\gamma$-phosphoryl group as interpreted from the crystal structure of $\mathrm{MDD}_{\mathrm{SE}}$-FMVAPP-ATP $\gamma \mathrm{S}^{18}$ (Supplementary Fig. 4), and mutation of this residue had been shown to decrease MDD enzymatic activity drastically ${ }^{17}$. Surprisingly, we have found that this conserved S106 composes a part of one of the metal-binding sites in the open (MDD $\left.\mathrm{MF}_{\mathrm{E}}-\mathrm{MVAPP}-\mathrm{AMPPCP}-\mathrm{Mg}^{2+}\right)$ and closed $\left(\mathrm{MDD}_{\mathrm{EF}}-\mathrm{MVAPP}-\mathrm{ADPBeF}_{3}-\mathrm{Mg}^{2+}\right)$ conformations of $\mathrm{MDD}_{\mathrm{EF}}$, 
a

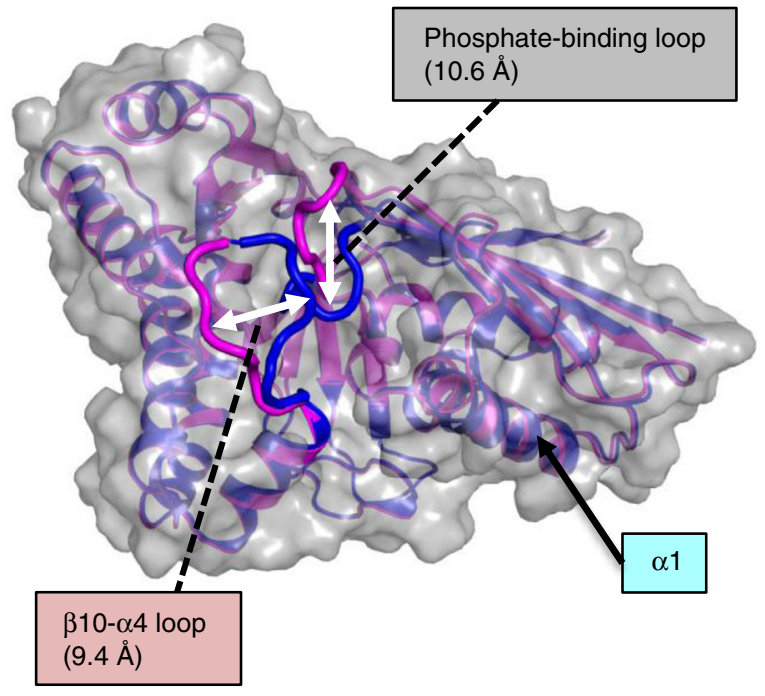

b $\quad \alpha \alpha$ distances between open and closed conformations

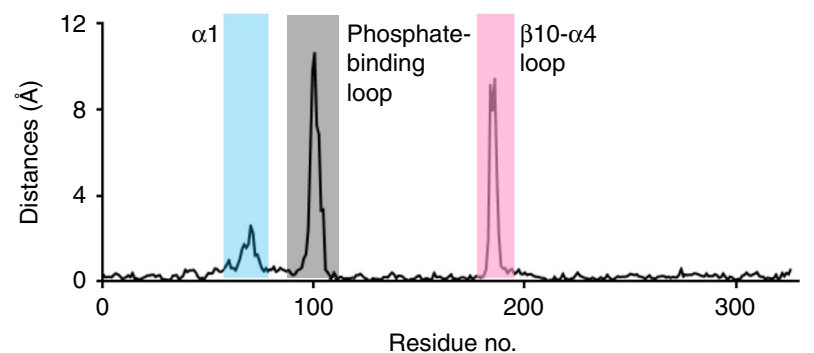

Fig. 4 Differences between open and closed $M \mathrm{MD}_{\mathrm{EF}}$ bound with ligands. a Superposition of open (MDD $\mathrm{EF}-\mathrm{MVAPP}-\mathrm{AMPPCP}-\mathrm{Mg}^{2+}$, magenta) and closed $\left(\mathrm{MDD}_{\mathrm{EF}}-\mathrm{MVAPP}-\mathrm{ADPBeF}_{3}-\mathrm{Mg}^{2+}\right.$, blue) conformations of $\mathrm{MDD}_{\mathrm{EF}}$. $A$ gray surface represents the envelope of the apo-MDD $D_{E F}$. The greatest distance between the $\beta 10-\alpha 4$ loops is $9.4 \AA$ (left white arrow) determined by measuring the distance between $\mathrm{K} 187 \mathrm{C} \alpha$ carbons in the open and closed structures. The greatest distance between the phosphate-binding loops is $10.6 \AA$ (right white arrow) determined by measuring the distance between A101 C $\alpha$ carbons in open and closed structures. $\mathbf{b}$ Distances of $\mathrm{C} \alpha$ atoms between open and closed conformations. The structural models of open and closed $M D D_{E F}$ were $C \alpha$-aligned to apo-MDD $D_{E F}$ with r.m.s. deviation values of 0.35 and $0.40 \AA$, respectively. The distances between corresponding $\mathrm{C} \alpha$ atoms in both structures is plotted as a function of residue number. The regions of helix $\alpha 1$ ( $\alpha 1,66-81)$, the phosphate-binding loop (97-104) and the $\beta 10-\alpha 4$ loop (183-190) are highlighted in cyan, gray, and pink, respectively. Source data are provided as a Source Data file.

taking the same position as previously assigned to the $\gamma$ phosphate.

Helix a4 moves from state I to state II (Fig. 5e, right), with the conserved S191 on the N terminus of helix a 4 forming contacts with the pyrophosphate of MVAPP (Fig. 2b; Supplementary Table 3$)^{17}$. Although the position of helix a4 in the three MVAPP-bound $\mathrm{MDD}_{\mathrm{EF}}$ structures showed no significant change (Fig. 5e, right), the side-chain orientation of S191 in the closed conformation ( $\mathrm{MDD}_{\mathrm{EF}}-\mathrm{MVAPP}-\mathrm{ADPBeF}_{3}-\mathrm{Mg}^{2+}$ ) changes to interact with conserved K187, resulting in loss of contacts with MVAPP. In summary, the angular changes in helix $\alpha 1, \alpha 2$, and $\alpha 4$ are consistent with the dynamic interactions between key residues and ligands (Supplementary Tables 4 and 5). These differences in the apo and ligand-bound $\mathrm{MDD}_{\mathrm{EF}}$ structures here reveal a coordinated set of programmed conformational rearrangements around the active site region upon each step of substrate binding during the catalytic reaction.
The role of conserved $\mathrm{K} 187$ in the non-conserved $\beta 10-\alpha 4$ loop. In the closed $\mathrm{MDD}_{\mathrm{EF}}$ structure ( $\left.\mathrm{MDD}_{\mathrm{EF}}-\mathrm{MVAPP}-\mathrm{ADPBeF}_{3}-\mathrm{Mg}^{2+}\right)$, the non-conserved $\beta 10-\alpha 4$ loop covers the active site (Fig. 4 ), and K187 in the $\beta 10-\alpha 4$ loop extends its side-chain into the active site to interact with $\mathrm{S} 191$ and the bridging oxygen of $\mathrm{ADPBeF}_{3}$ (Fig. $5 \mathrm{~d}$, right). Lysine/arginine residues are known for substrate binding or neutralizing the negatively charged active site in kinases ${ }^{38,39}$. In $\mathrm{MDD}_{\mathrm{EF}}, \mathrm{K} 71$ and R144 function for MVAPP binding and may also fulfill a neutralization role (Fig. 2b). The K187 residue is conserved among the MDD family of proteins (Fig. 6a), and mutation of the corresponding lysine (K208A in rat MDD) resulted in a dead enzyme $^{40}$. This experimental evidence indicates that this lysine is critical for the enzyme reaction. To investigate the function of this lysine residue, a K187A mutant of $\mathrm{MDD}_{\mathrm{EF}}$ was created and the K187A mutant protein was purified and examined (see "Methods" section; Supplementary Fig. 5). The K187A mutant showed a nearly-dead enzymatic activity of $0.35 \%$ compared with the wildtype enzyme at saturated substrate concentrations. A 300 fold decrease in enzymatic activity confirms the essentiality of K187 in the reaction (Fig. 6b). To differentiate the role of K187 in either catalysis or substrate binding, ITC was then employed to determine $K_{\mathrm{d}}$ values under different conditions ${ }^{41}$. All the derived thermodynamic parameters are listed in Supplementary Table 6.

The $K_{\mathrm{dATP} \gamma \mathrm{S}}$ values were determined under different conditions with the K187A mutant alone or the K187A mutant pre-incubated with MVAPP (see "Methods" section). The $K_{\mathrm{dATP}} \mathrm{s}$ value between ATP $\gamma$ S and the K187A mutant is $182 \pm 36 \mu \mathrm{M}$, similar to the value of $K_{\mathrm{dATP} Y \mathrm{~S}}$ of wild-type $\mathrm{MDD}_{\mathrm{EF}}(215 \pm 8 \mu \mathrm{M})^{24}$. However, in the presence of MVAPP, $K_{\mathrm{dATP} \gamma \mathrm{S}}$ is $58.2 \pm 13.2 \mu \mathrm{M}$ (Fig. 6c), which is only about two-fold higher than the $K_{\mathrm{dATP} \gamma \mathrm{S}}$ value of wild-type $\mathrm{MDD}_{\mathrm{EF}}(25.4 \pm 5.5 \mu \mathrm{M})^{24}$, suggesting that K187 has key roles mainly in catalysis. The side-chain of K187 is at a hydrogen bond distance to the $\beta-\gamma$ bridging oxygen in $\mathrm{MDD}_{\mathrm{EF}}-\mathrm{MVAPP}$ $\mathrm{ADPBeF}-\mathrm{Mg}_{3}^{2+}$. This positively charged side-chain, together with the $\mathrm{Mg}^{2+}$ ions, could relieve a negatively charged environment built up upon substrate binding and during the phosphoryl transfer reaction ${ }^{42}$. The present results suggest that K187 can be transiently involved in the reaction, and the conserved S191 may confer initially a site for MVAPP binding and later an anchoring point for accommodating K187 in the active site for enzyme catalysis.

\section{Discussion}

The four structures presented here clearly represent different states of $\mathrm{MDD}_{\mathrm{EF}}$ during the enzymatic reaction. Based on these experimental observations, we suggest a model for interpreting the physical steps of the $\mathrm{MDD}_{\mathrm{EF}}$ enzymatic reaction upon the ordered substrate binding of the sequential ordered bi-substrate mechanism. In the physical mechanism, the phosphate-binding loop and the $\beta 10-\alpha 4$ loop may be initially dynamic or disordered in an apo structure (Fig. 7a, left). Upon MVAPP binding, induced structural changes take place in the $\beta 10-\alpha 4$ loop and three $\alpha$ helices ( $\alpha 1, \alpha 2$, and $\alpha 4)$ (Fig. 7a, middle-left). The movements of helix $\alpha 2$ and $\alpha 1$ reposition S106 and Q68 to facilitate ATP and metal binding, as experimentally supported by previous ITC results ${ }^{24}$. The initial binding of ATP stabilizes the phosphatebinding loop (Fig. 7a, middle-right). The phosphate tail of ATP, S106 and the pyrophosphate of MVAPP form the first metalbinding site. Subsequent structural rearrangement occurs and the phosphate-binding loop bends down to "drag" ATP into its catalytically favored position (Supplementary Fig. 6a, b). The recognition of the $\beta$ - $\gamma$-bridging oxygen of ATP by the phosphatebinding loop may therefore be a checkpoint during enzyme catalysis. The second metal is fit into the active site, followed by the two loops closing the substrate entrance (Fig. 7a, right). In the 
a
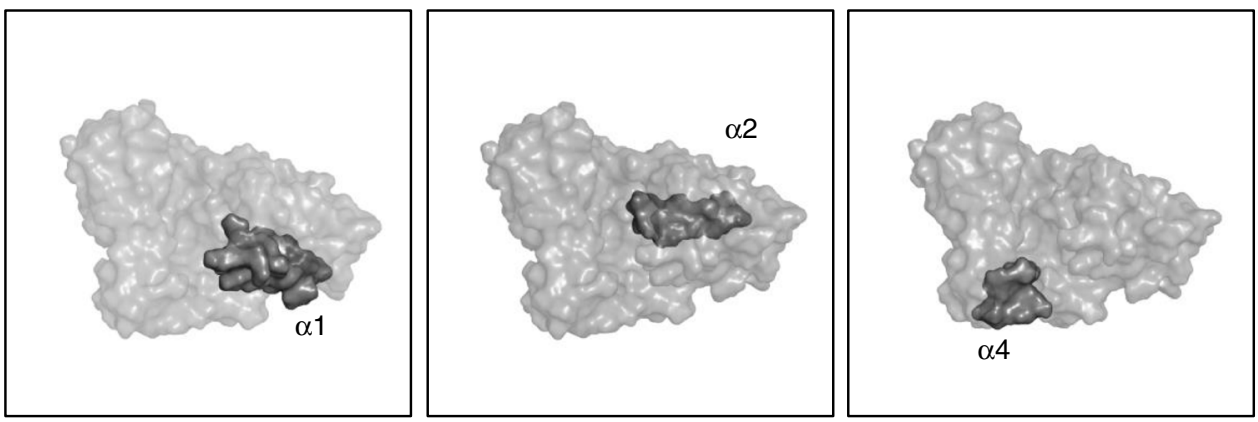

b
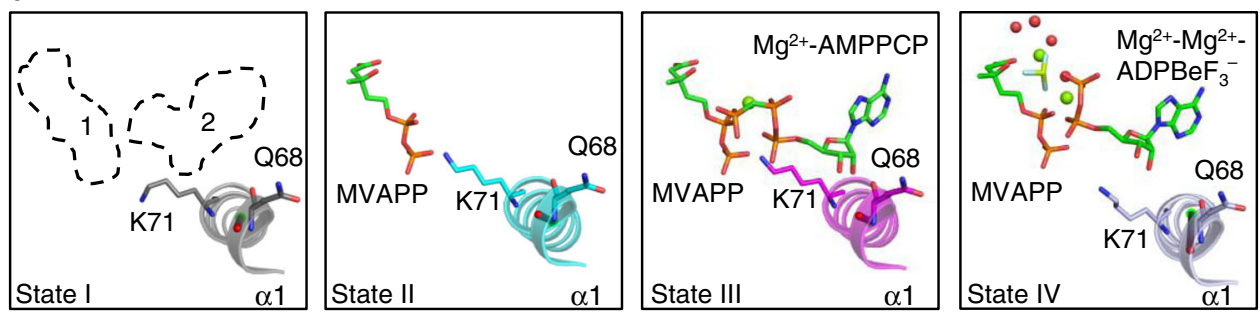

C
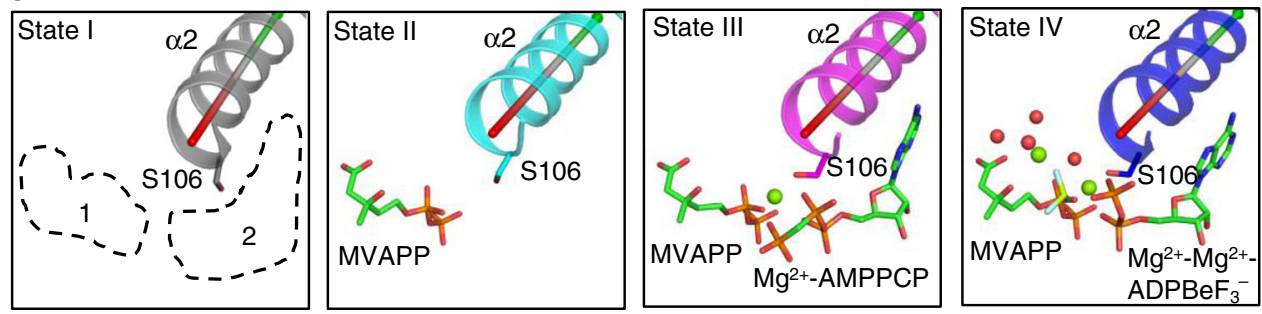

d
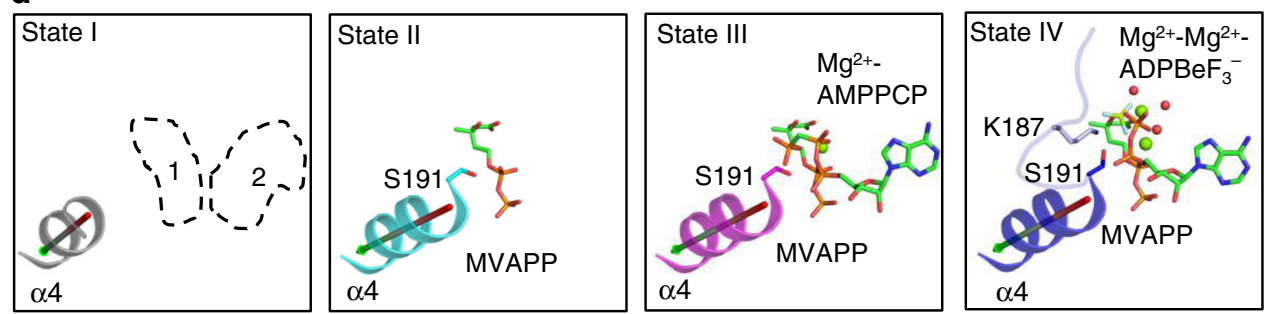

e
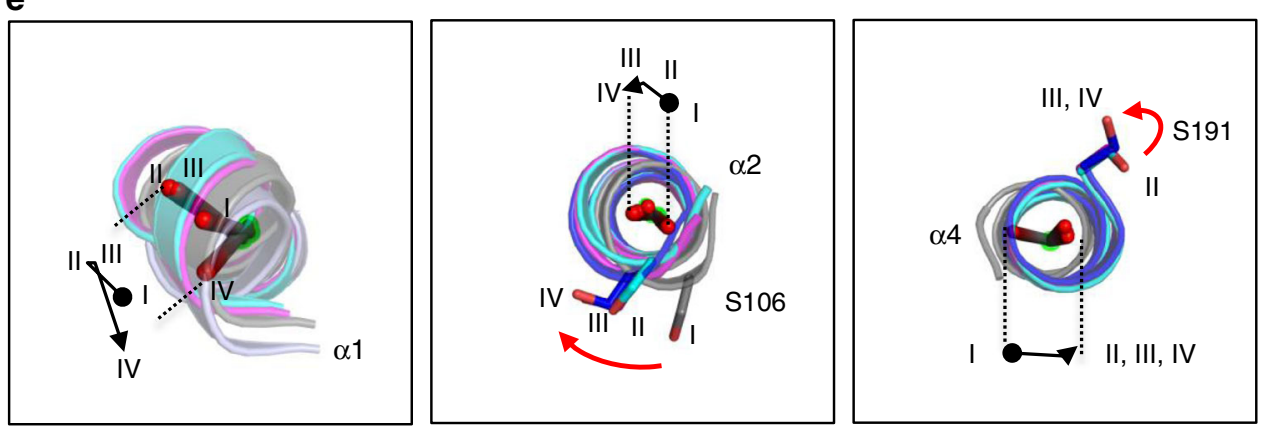

Fig. 5 Movements of helix $\boldsymbol{\alpha 1} \mathbf{\alpha 2}$, and $\boldsymbol{\alpha} \mathbf{4}$ in the unbound and ligand-bound $\mathbf{M D D}_{\mathbf{E F}}$. a Locations of helix $\alpha 1$ (left), $\alpha 2$ (middle), and $\alpha 4$ (right) in MDD b Positions of helix $\alpha 1$ and key residues (Q68 and K71) in four different structures (left: apo-MDD $D_{E F}$, gray, state l; middle-left: MDD II; middle-right: $\mathrm{MDD}_{\mathrm{EF}}-\mathrm{MVAPP}-\mathrm{AMPPCP}-\mathrm{Mg}^{2+}$, magenta, state III; right: $\mathrm{MDD}_{\mathrm{EF}}-\mathrm{MVAPP}^{2} \mathrm{ADPBeF}-\mathrm{Mg}^{2+}$, blue, state IV). The binding sites of MVAPP (1) and ATP (2) are circled with dashed lines. The center of helix $\alpha 1$ is shown as a rod colored in red ( $\mathrm{N}$ terminus) and green ( $\mathrm{C}$ terminus). Magnesium ions and water molecules are shown as green and red spheres, respectively. c Position of helix $\alpha 2$ and key residues (S106) in four different structures as described in b. d Position of helix $\alpha 4$ and key residues (S191) in four different structures as described in $\mathbf{b}$. K187 in the $\beta 10-\alpha 4$ loop (right panel) is shown as a stick model. e Superposition of helix $\alpha 1$ (left), $\alpha 2$ (middle), and $\alpha 4$ (right) from four different structures. The helical movements of $\alpha 1, \alpha 2$, and $\alpha 4$ upon substrate binding are drawn in black lines. The key residues, S106 and S191, in the middle and right panels are shown in stick and the side-chain movements are drawn in red lines. 
a

Enterococcus faecalis
Enterococcus faecalis
Enterococcus faecium
Staphylococcus epidermidis
Staphylococcus aureus
Streptococcus pyogenes
Listeria monocytogenes
Homo sapiens
Trypanosoma brucei
Mus musculus
Xenopus tropicalis
Bos taurus
Arabidopsis thaliana

Functionally annotated MVAPP binding

ATP or analogue binding

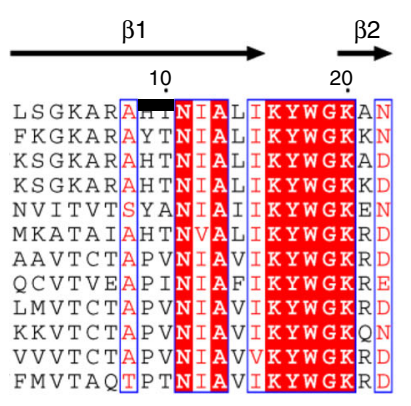

$\begin{array}{cc}\Delta \\ n^{2} & \Delta\end{array}$
Phosphate-binding loop

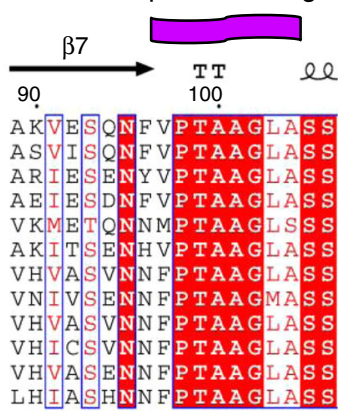

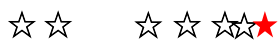

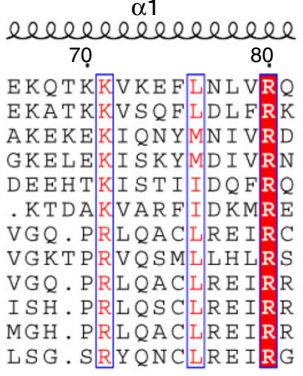

is 猔

$\beta 10-\alpha 4$ loop

\section{Enterococcus faecalis \\ Enterococcus faecalis Enterococcus faecium Staphylococcus epidermidis Staphylococcus aureus Streptococcus pyogenes Listeria monocytogenes Homo sapiens \\ Homo sapiens
Trypanosoma brucei \\ Mus musculus \\ Xenopus tropicalis \\ Bos taurus \\ Arabidopsis thaliana}

Functionally annotated

MVAPP binding

ATP or analogue binding

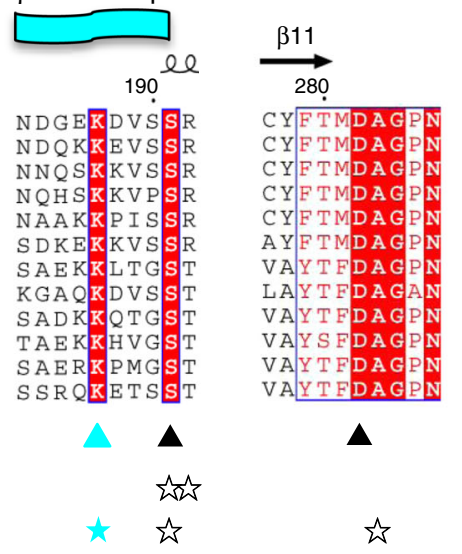

K187A mutant

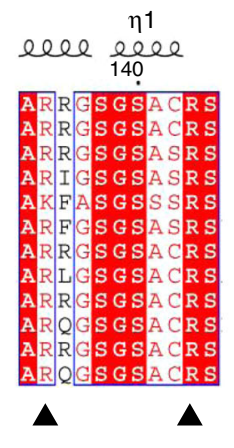

证通证
$0.35 \pm 0.01$

b

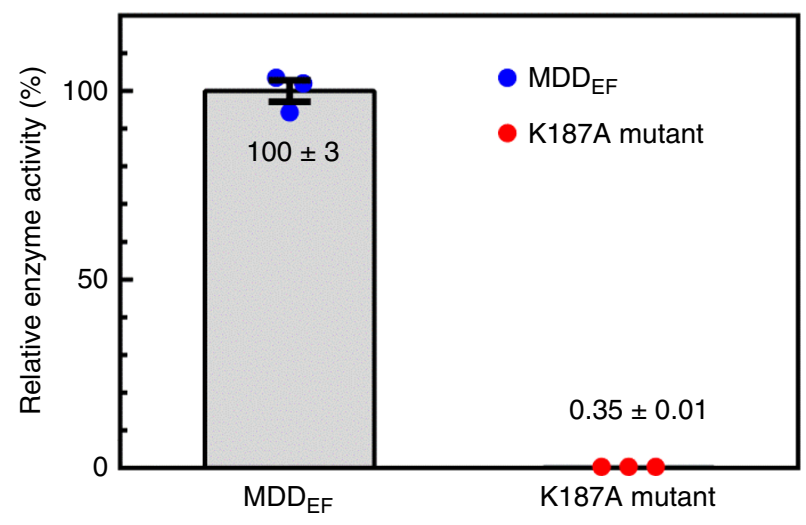

C

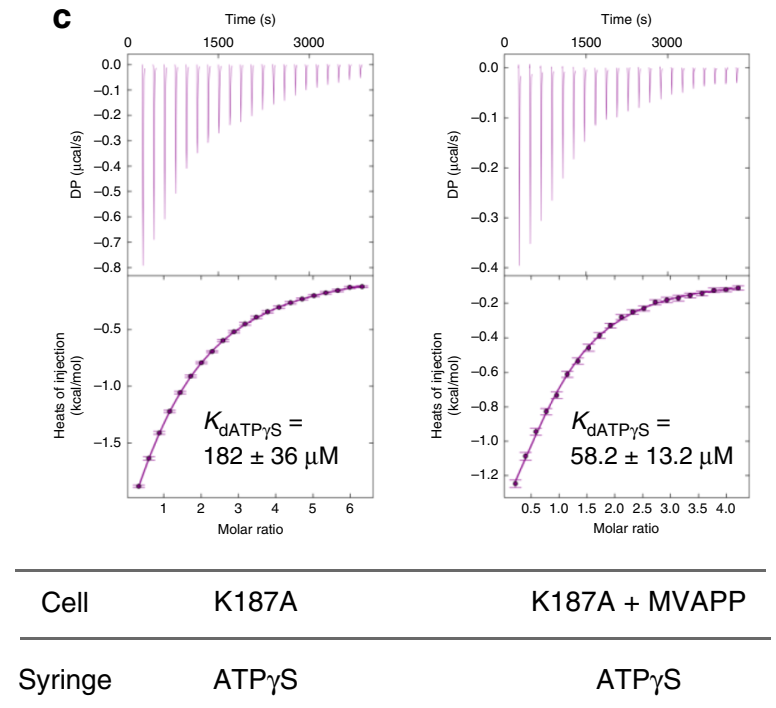

Fig. 6 The key residue, K187, involved in enzyme catalysis. a Partial sequence alignment results of the MDD family of proteins (see "Methods" section for details). Identical residues are highlighted in red. Homologous residues have their one-letter codes in red. Residues characterized to be functionally important among MDD proteins are marked by solid triangles $17,18,40$. Residues involved in substrate interaction are marked by empty stars and color-filled stars (red: S106; cyan: K187). The phosphate-binding loop and the $\beta 10-\alpha 4$ loop are indicated with curved ribbons in magenta and cyan, respectively. b Relative enzyme activity of the K187A mutant and the wild-type MDD $D_{\mathrm{EF}}$. The enzyme activities of $\mathrm{MDD}_{\mathrm{EF}}$ and K187A mutant of MDD $\mathrm{EF}_{\mathrm{F}}$ were determined at saturating concentrations of two substrates (MVAPP $=200 \mu \mathrm{M} ; \mathrm{MgATP}=800 \mu \mathrm{M})$ and normalized by the means of wild-type MDD enzyme activity ( $n=3$ independent experiments). The means and the standard error (SEM) were derived from each triplicate. Source data are provided as a Source Data file. c ITC experiments of $\mathrm{MDD}_{\mathrm{EF}}$ and the K187A mutant. Left: the K187A mutant (100 $\left.\mu \mathrm{M}\right)$ was titrated with ATP $\gamma \mathrm{S}$ ( 3 mM). Right: the K187A mutant $(100 \mu \mathrm{M})$ was pre-incubated with MVAPP $(1 \mathrm{mM})$ and then titrated with ATP $\gamma \mathrm{S}(2 \mathrm{mM})$. The thermodynamic parameters of each experiment are listed in Supplementary Table 6 . The protein concentration was adjusted to $100 \mu \mathrm{M}$ and all the protein and titrants were dissolved in the buffer containing $100 \mathrm{mM}$ HEPES, $\mathrm{pH} 7,100 \mathrm{mM} \mathrm{KCl}$ and $10 \mathrm{mM} \mathrm{MgCl}$. Error bars in $\mathbf{b}$ and $\mathbf{c}$ represent standard error of the mean (SEM). 
a Apo

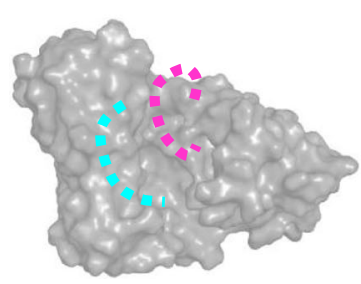

MVAPP-bound

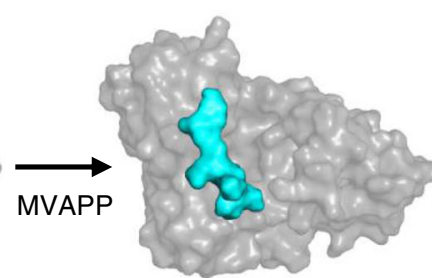

Two-substrate-bound open

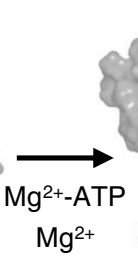

Two-substrate-bound close

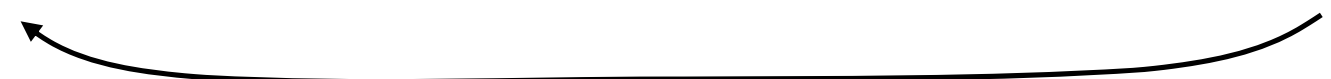

Catalysis \& product release

b

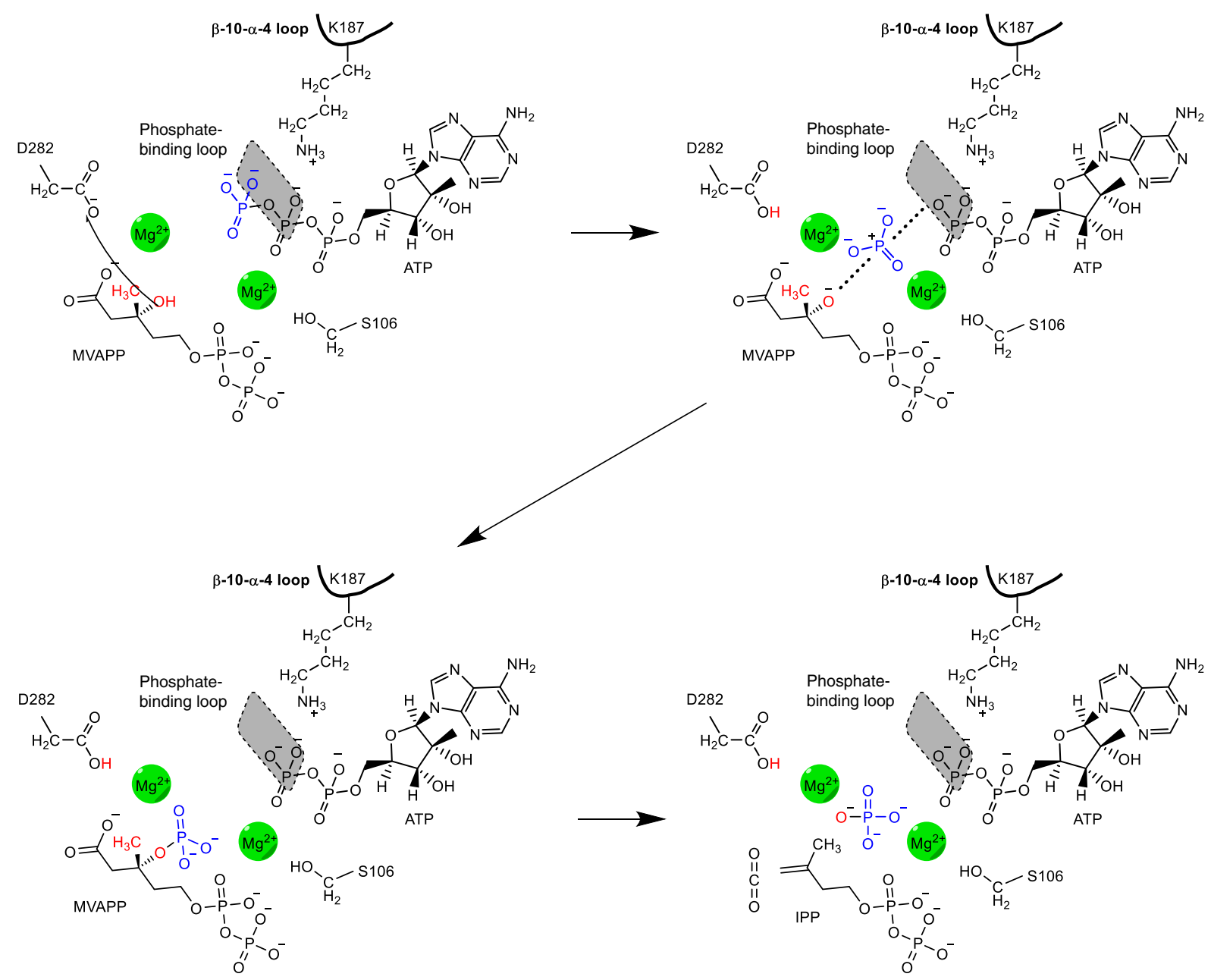

Fig. 7 Proposed model for the detailed MDD enzyme mechanism. a Changes in the $M_{D D} D_{E F}$ structure upon substrate binding. Left: unbound MDD ${ }_{E F}$. Middle-left: MVAPP-bound $M{ }^{2} D_{E F}$; the $\beta 10-\alpha 4$ loop is presented as cyan surface. Middle-right: an open conformation of MDD $D_{\mathrm{EF}}$ bound with MVAPP and ATP; the $\beta 10-\alpha 4$ loop and the phosphate-binding loop are shown in cyan and magenta surfaces. Right: a closed conformation of $\mathrm{MDD}_{\mathrm{EF}}$ bound with both substrates after conformational rearrangement; the $\beta 10-\alpha 4$ loop and the phosphate-binding loop are shown in cyan and magenta surfaces. Enzyme catalysis occurs after these two loops close the active site entrance, followed by product release (isopentenyl diphosphate (IPP), ADP, $\mathrm{CO}_{2}$, and phosphate). b Dissociative phosphoryl transfer mechanism of $M D D_{E F}$ during enzyme catalysis. Top-left: D282 is orienting the $3^{\prime}-\mathrm{OH}$ group of $\mathrm{MVAPP}$ (red). Top-right: dissociative phosphoryl transfer occurs and the metaphosphate (blue) is produced. Bottom-left: the metaphosphate attaches to the $3^{\prime}$ oxygen (red) of MVAPP and the proton is transferred to the transferred phosphate group. Bottom-right: dephosphorylation and decarboxylation occur and produce products, IPP, ADP, phosphate, and $\mathrm{CO}_{2}$. K187 from the $\beta 10-\alpha 4$ loop and metal ions in the active site are involved in neutralizing the negatively charged environment and assist catalysis. The phosphate-binding loop (shown as a gray shadow as it is in a plane above the rest of the figure) is involved in the ATP binding in the closed form of the $\mathrm{MDD}_{\mathrm{EF}}$ conformation. 
closed conformation, the side-chain of S191 rotates to provide an anchoring point for a transient stay of K187 in the active site. The conserved lysine residue has roles mainly in catalysis. After the chemical steps of catalysis, products (IPP, $\mathrm{ADP}, \mathrm{CO}_{2}$, and phosphate) are released from the enzyme and another enzymatic reaction takes place. These findings provide a comprehensive view of structural changes, which link to the specific function of each component orchestrated in the active site of MDD during the reaction.

In other MDD structures, different conformations of the $\beta-\alpha$ loop (corresponding to the $\beta 10-\alpha 4$ loop in $\mathrm{MDD}_{\mathrm{EF}}$ ) and the phosphate-binding loop have been determined. That may be the consequence of the flexibility of these two loops in the MDD family of proteins. In the present structural study, the positions of two loops were determined in the ligand-bound $\mathrm{MDD}_{\mathrm{EF}}$ struc-

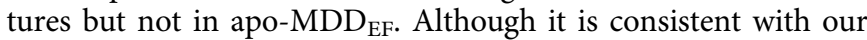
previous study on $\mathrm{MDD}_{\mathrm{EF}}$ in which a MVAPP-mediated ATPbinding mechanism upon substrate binding was suggested ${ }^{24}$, our results are different from other published structures of MDD proteins, in which both or either loops are ordered in the apo structures of MDDs.

The published MDD structures have been compared and summarized in Supplementary Table 1. Among the apo-MDD structures, only the apo-MDD $\mathrm{EF}(5 \mathrm{~V} 2 \mathrm{M}, 6 \mathrm{E} 2 \mathrm{~S})$ and apo-MDD $\mathrm{SE}$ (3QT5) structures have no defined electron densities of the $\beta-\alpha$ loops. It was observed that the presence of the $\beta-\alpha$ loop in these apo structures is accompanied by the well-defined upcoming $\alpha$ helix and the direct crystal contacts either in the $\beta-\alpha$ loop or in a region adjacent to the preceding $\beta 10$ strand ( $\alpha 8 \quad \eta 4 \quad \beta 13$ in $\mathrm{MDD}_{\mathrm{EF}}$, Fig. 1; Supplementary Fig. 7a). In $\mathrm{MDD}_{\mathrm{SE}}-\mathrm{MVAPP}$ (4DU7), the posterior $\alpha$-helix density is well-defined and the density of the $\beta$ - $\alpha$ loop can also be observed if compared with the apo form of $\mathrm{MDD}_{\mathrm{SE}}$ (3QT5). This suggests that the binding of MVAPP stabilizes the posterior $\alpha$-helix and the $\beta$ - $\alpha$ loop, consistent with our present results. In the structures of MDDs bound with MVAPP, only $\mathrm{MDD}_{\mathrm{EF}}(6 \mathrm{E} 2 \mathrm{~T})$ has an undefined phosphatebinding loop. Other MVAPP-bound MDDs have stabilized phosphate-binding loops possibly due to crystal contacts directly involving this loop or the C-terminal insertion covering the corresponding $\beta$-strands in eukaryotic MDDs (Supplementary Table 1). In contrast to all other published structures, in the $\mathrm{MDD}_{\mathrm{EF}}$ structures, there is no crystal contact in the regions described above, which should allow the flexible loops to take up unrestricted conformations. This also may be one of the reasons that different ligand-bound $\mathrm{MDD}_{\mathrm{EF}}$ structures can be obtained by soaking experiments.

The MDD enzyme mechanism involves phosphoryl transfer of $\gamma$-phosphate of ATP to the $3^{\prime}$-oxygen of MVAPP ${ }^{17,28}$. However, how the $\gamma$-phosphoryl group of ATP transfers to MVAPP is unclear. In $\mathrm{MDD}_{\mathrm{EF}}-\mathrm{MVAPP}-\mathrm{ADPBeF}_{3}-\mathrm{Mg}^{2+}$, the distance between the phosphoryl donor (O $\beta$ of ADP) and the acceptor $\left(3^{\prime}\right.$ $\mathrm{O}$ of MVAPP) is $5.7 \AA$ and $\mathrm{BeF}_{3}-$ is located in the in-line phosphoryl transfer position (Supplementary Fig. 1). "Pauline bond order" is frequently used for describing a phosphoryl transfer reaction belonging to either an associative or dissociative mechanism in protein kinases or phosphatases ${ }^{39}$. Based on the distance information from the structural model of $\mathrm{MDD}_{\mathrm{EF}^{-}}$ MVAPP-ADPBeF $3-\mathrm{Mg}^{2+}$, the bond order was calculated (Supplementary Note 1 and Supplementary Eq. 1) and estimated to be 0.014 , corresponding to $1.4 \%$ associative and $98.6 \%$ dissociative. If the standard coordinate error $(0.18 \AA)^{43,44}$ in the structure is considered, the bond order in the transition state of phosphoryl transfer could range from 0.007 ( $99.3 \%$ dissociative) to 0.027 (97.3\% dissociative). In the active site of the closed complex structure, the ligands were packed tightly, and any movement of MVAPP and/or ADP would result in steric clashes. Thus, our structural findings suggested that the phosphoryl transfer step in the reaction would likely belong to dissociative phosphoryl transfer, in which metaphosphate $\left(\mathrm{PO}_{3}{ }^{-}\right)$transiently existed during catalysis. These conclusions are also consistent with a recently published $\mathrm{QM} / \mathrm{MM}$ study in which the active site environment of MDD was generated based on pyruvate kinase (PDB: $3 \mathrm{HQP})^{45}$. The second metal may also be involved in changing the position the $\gamma$-phosphate from ATP to approach the $3^{\prime}$-oxygen of MVAPP to facilitate the reaction.

Although the conserved Asp in MDDs (D282 in $\mathrm{MDD}_{\mathrm{EF}}$ ) was previously suggested as a general base for the deprotonation of $3^{\prime}$ $\mathrm{OH}$ of MVAPP, which then triggers nucleophilic attack on the $\gamma$ phosphate of ATP to initiate phosphoryl transfer, a recent study on MDD from Sulfolobus solfataricus $\left(\mathrm{MDD}_{\mathrm{SS}}\right)$ has shown that the D281T or D281V mutants produce the $3^{\prime}$-phopshate-MVAPP intermediate but not the final product, IPP. These suggest that the conserved Asp in MDDs may be involved in a later step, as the dephosphorylation and decarboxylation ${ }^{28}$. However, the production of $3^{\prime}$-phopshate-MVAPP by the D281T or D281V mutants is much slower than the production of IPP by the wildtype $\mathrm{MDD}_{\mathrm{SS}}$, somewhat a puzzling result if the conserved Asp is not at all involved in phosphoryl transfer.

From structural observations, we suggest that this conserved Asp may have multiple roles in MDD catalysis. It has been suggested that the "catalytic" Asp in the active site of kinases could confine the position of the hydrogen of the hydroxyl group of a substrate through hydrogen bond interactions and thus prepare a productive rotamer of the hydroxyl group for phosphoryl transfer $^{42}$. It has also been shown that in a dissociative phosphoryl transfer reaction, the substrate could remain protonated before and during the transition state ${ }^{46}$. In the case of $\mathrm{MDD}_{\mathrm{EF}}$, the carboxyl group of D282 is $3.3 \AA$ apart from the $3^{\prime}$-oxygen of MVAPP. This suggests that one of the roles of Asp in MDDs is to orient the $3^{\prime} \mathrm{OH}$ group of MVAPP through hydrogen bonding in a position for an effective phosphoryl transfer. Although a low $\mathrm{pH}$ environment would affect the protonation states of catalytic residues and substrates, resulting in a decrease in enzymatic activity 47 , MDD enzymes remain active under acidic conditions (above $\mathrm{pH} 3)^{48,49}$ and D282 of $\mathrm{MDD}_{\mathrm{EF}}$ under our crystallization conditions ( $\mathrm{pH} 4.6$ ) remains $80 \%$ un-protonated (Supplementary Note 1 and Supplementary Eq. 2, assuming the pKa value of the carboxyl group of D282 is 3.9), supporting its role in confining the hydrogen of the $3^{\prime}-\mathrm{OH}$ group of MVAPP in a certain orientation during dissociative phosphoryl transfer. However, it remains unclear what could serve as a proton acceptor after the formation of the $3^{\prime}$-phophate-MVAPP intermediate in the case of MDD catalysis, although the transferred phosphate moiety could play that role ${ }^{28}$. In addition, the structural studies on the enzymatically dead D283A mutant of $\mathrm{MDD}_{\mathrm{SE}}(4 \mathrm{DPW})$ showed that the binding pose of MVAPP in the complex structure of $\mathrm{MDD}_{\mathrm{SE}}$ D283A-MVAPP-ATP $\gamma S$ differs from that in other MDD-ligandbound structures and the carboxyl group of MVAPP does not interact with its binding partner R144 ${ }^{18}$. This suggests that the conserved Asp may have an implied function for preventing noncatalytically binding of MVAPP in the active site. This may also be the case in the D281T or D281V mutants of MDD $\mathrm{Ss}_{\text {. }}$

The current hypothesis for the MDD enzyme mechanism also suggests that the catalytic Asp residue facilitates dephosphorylation/decarboxylation of $3^{\prime}$-phosphate-MVAPP either by changing the conformation of the $3^{\prime}$-phosphate-MVAPP via negative charge repulsion or by stabilizing the carbocation intermediate right after dephosphorylation of the $3^{\prime}$-phosphate$\mathrm{MVAPP}^{28}$. From our crystal structure of $\mathrm{MDD}_{\mathrm{EF}^{-}-\mathrm{MVAPP}-}$ $\mathrm{ADPBeF}{ }_{3}-\mathrm{Mg}^{2+}$, large conformational changes of $3^{\prime}$-phosphateMVAPP might not happen in such packed active site environment. Therefore, stabilizing the carbocation intermediate by the 
conserved Asp could be a plausible model, although the influence of metal ions in the transition state remains unclear.

Based on these considerations, we have proposed a possible model for demonstrating the chemical steps of $\mathrm{MDD}_{\mathrm{EF}}$ catalysis. In the closed complex structure of $\mathrm{MDD}_{\mathrm{EF}}$ bound with metals, MVAPP and ATP, D282 confine the $3^{\prime}-\mathrm{OH}$ of MVAPP to prepare a phosphate acceptor (Fig. 7b, top-left); second, metaphosphate transiently exists during the transition state (Fig. 7b, top-right); third, MVAPP receives metaphosphate to produce a $3^{\prime}$-phosphate-MVAPP intermediate (Fig. 7b, bottom-left). Lastly, dephosphorylation and decarboxylation of the intermediate occurs to produce products, IPP, $\mathrm{CO}_{2}$, phosphate, and ADP (Fig. 7b, bottom-right).

In summary, our findings provide detailed information of the $\mathrm{MDD}_{\mathrm{EF}}$ enzyme mechanism in the aspects of substrate binding and catalysis. These results provide detailed roles for conserved residues and identify the binding sites for two magnesium ions involved in catalysis. Movements in two unrestricted loops and three helices sequentially build the active site and define a potential checkpoint for enzyme activity. Finally, the structures in these different forms will serve as platforms for structure-based drug development, where this work can also be applied to the control of bacterial infections caused by multidrug-resistant Staphylococci, Streptococci, and Enterococci.

\section{Methods}

Preparation of recombinant $\mathrm{MDD}_{\mathrm{EF}}$ and the K187A mutant. A modified sitedirected mutagenesis method ${ }^{50}$ was used to create the K187A mutant of $\mathrm{MDD}_{\mathrm{EF}}{ }^{5}$ The sequence of the forward primer from $5^{\prime}$ to $3^{\prime}$ is "CTTAATTAATGATGGC GAAGCAGATGTTTCCAGCCGTGATG", and the sequence of the reverse primer is "CATCACGGCTGGAAACATCTGCTTCGCCA TCATTAATTAAG". The $50 \mu \mathrm{l}$ PCR solution contained the forward and reverse primers $(1 \mu \mathrm{M}$, respectively), dNTP $(200 \mu \mathrm{M}$ of each), Phusion HF buffer $(1 \times)$, template DNA (0.1-1 $\mu$ l), DMSO (2\%), Phusion DNA polymerase (one unit) and sterile water. The PCR program was set to be 1 cycle of denaturation $\left(95^{\circ} \mathrm{C}, 1 \mathrm{~min}\right), 25$ cycles of the three-step reaction (1. Denaturation, $95^{\circ} \mathrm{C}, 30 \mathrm{~s} ; 2$. Annealing, $62^{\circ} \mathrm{C}, 30 \mathrm{~s} ; 3$. Extension, $72^{\circ} \mathrm{C}$, $5.5 \mathrm{~min})$ and one cycle of the final extension $\left(72^{\circ} \mathrm{C}, 10 \mathrm{~min}\right)$. After PCR, the original templates containing methylated DNA were digested by Dpnl $(1 \mu \mathrm{l})$ for $1 \mathrm{~h}$ at $37^{\circ} \mathrm{C}$. The K187A mutant construct was transformed into Escherichia coli BL21 (DE3, Novagen). Transformed cells were cultured in LB broth (containing $50 \mathrm{mg} \mathrm{ml}^{-1}$ kanamycin) at $37^{\circ} \mathrm{C}$ to an $\mathrm{A}_{600 \mathrm{~nm}}$ value of $0.8-1.0$. The protein expression and purification procedures for the K187A mutant were similar to the procedures for obtaining wild-type $\mathrm{MDD}_{\mathrm{EF}}$ proteins ${ }^{24}$. Protein expression of K187A was conducted by adding isopropyl 1-thio- $\beta$-D-galactopyranoside (IPTG) $(0.1 \mathrm{mM})$ to the bacterial culture for $4 \mathrm{~h}$ at $37^{\circ} \mathrm{C}$. Cells were harvested by centrifugation at $9605 \mathrm{~g}$, resuspended in binding buffer $(50 \mathrm{mM}$ sodium phosphate at $\mathrm{pH} 7.4,300 \mathrm{mM} \mathrm{NaCl}$, and $10 \mathrm{mM}$ imidazole), and lysed to homogeneity by French Press. His-tagged K187A proteins were trapped on a $\mathrm{Ni}^{2+}-\mathrm{NTA}$ column followed by elution with an increasing percentage of elution buffer $(50 \mathrm{mM}$ sodium phosphate at $\mathrm{pH} 7.4,300 \mathrm{mM} \mathrm{NaCl}$, and $300 \mathrm{mM}$ imidazole). Eluted fractions were examined by SDS-PAGE and fractions containing K187A were collected and dialyzed against dialysis buffer $(25 \mathrm{mM}$ Tris- $\mathrm{HCl}, \mathrm{pH} 8.0,100 \mathrm{mM} \mathrm{NaCl}$, and 10 $\left.\mathrm{mM} \mathrm{MgSO}_{4}\right)$ for two times, one with $\beta$-mercaptoethanol $(\beta-\mathrm{ME})(20 \mathrm{mM})$ and the other one without $\beta$-ME. The N-terminal His-tag was removed from K187A by recombinant tobacco etch virus (TEV) protease treatment in dialysis buffer containing $1 \mathrm{mM}$ DTT and $0.5 \mathrm{mM}$ EDTA, followed by dialysis against the dialysis buffer without DTT and EDTA. His-tagged TEV and residual His-tagged K187A were removed by passing the protein mixture through a nickel affinity resin. Purified K187A protein solution was concentrated to $8-10 \mathrm{mg} \mathrm{ml}^{-1}$ by ultrafiltration and stored at $-20{ }^{\circ} \mathrm{C}$ or $-80{ }^{\circ} \mathrm{C}$ for long-term storage.

Enzymatic activity of wild-type $\mathrm{MDD}_{\mathrm{EF}}$ and the K187A mutant. The $K_{\mathrm{mMVAPP}}$ value and the $K_{\mathrm{mATP}}$ value of $\mathrm{MDD}_{\mathrm{EF}}$ were $\sim 40$ and $\sim 160 \mu \mathrm{M}^{24}$, respectively. Enzymatic reactions for wild-type $\mathrm{MDD}_{\mathrm{EF}}$ and the K187A mutant were performed at saturated substrate concentrations $(\mathrm{MVAPP}=200 \mu \mathrm{M}, \mathrm{ATP}=800 \mu \mathrm{M})$. The enzymatic activities of $\mathrm{MDD}_{\mathrm{EF}}$ and the K187A mutant were determined using an ATP/NADH enzyme-coupled assay. Each reaction was performed at $30^{\circ} \mathrm{C}$ under the conditions (100 mM HEPES, pH 7.0, $100 \mathrm{mM} \mathrm{KCl,} 10 \mathrm{mM} \mathrm{MgCl}_{2}, 0.2 \mathrm{mM}$ $\mathrm{NADH}, 0.4 \mathrm{mM}$ phosphoenolpyruvate, 4 units of pyruvate kinase, 4 units of lactate dehydrogenase, and $100 \mathrm{nM} \mathrm{MDD} \mathrm{EF}^{18}$ or $1 \mu \mathrm{M}$ K187A). Initial velocity of each reaction was determined and relative enzymatic activity of the K187A mutant was calculated by dividing the enzymatic velocity of the K187A mutant by the enzymatic velocity of wild-type $\mathrm{MDD}_{\mathrm{EF}}$. Each assay has a final volume of $200 \mu \mathrm{l}$. Data analysis was performed using SigmaPlot verion 12.5 and GraphPad Prism 6.0.
Sequence alignment and structural annotation. The sequences of MDD proteins from organisms (Enterococcus faecalis; Enterococcus faecium; Staphylococcus epidermidis; Staphylococcus aureus; Streptococcus pyogenes; Listeria monocytogenes Homo sapiens; Trypanosoma brucei; Mus musculus; Xenopus tropicalis; Bos taurus; Arabidopsis thaliana) were aligned using EBI Clustal Omega ${ }^{52}$. The secondary structure elements were drawn using ESPript $3.0^{53}$ based on the structural model of $\mathrm{MDD}_{\mathrm{EF}}$ in complex with MVAPP, ADP, cobalt, and sulfate $\mathrm{MDD}_{\mathrm{EF}}$-MVAPP$\mathrm{ADP}-\mathrm{SO}_{4}^{2}-\mathrm{Co}^{2+}$ ) in this study.

Preparation of crystals of apo and ligand-bound $\mathbf{M D D}_{\mathrm{EF}}$. $\mathrm{MDD}_{\mathrm{EF}}$ was crystallized using the sitting drop method with $1.6 \mathrm{M}$ ammonium sulfate, $50 \mathrm{mM}$ sodium acetate, $\mathrm{pH} 4.6$, as established in our previously published results ${ }^{24}$. Buffer exchange procedures for ligand soaking experiments were performed by replacing the crystallization buffer with soaking buffer (26\% PEG3350, $5 \mathrm{mM} \mathrm{MgCl}_{2}, 50 \mathrm{mM}$ sodium acetate, $\mathrm{pH} 4.6$ ) and crystals were then equilibrated in soaking buffer for $10 \mathrm{~min}$. Each ligand was dissolved in soaking buffer to a final concentration of 2 $\mathrm{mM}$ and a small amount of ligand solution $(0.12-0.15 \mu \mathrm{l})$ was added into the drop for a one-day soaking procedure. For cryo-protection, dehydration buffer $(30 \%$ PEG3350, 15\% PEG400, $50 \mathrm{mM}$ sodium acetate, $\mathrm{pH}$ 4.6) was placed into the bottom well of each individual chamber in order to increase the PEG3350 concentration in the sitting drop and left for one day. Crystals of $\mathrm{MDD}_{\mathrm{EF}}$ soaked with ligands and metal ions were labeled in a manner of " $\mathrm{MDD}_{\mathrm{EF}}$-ligand-metal". Crystals with or without ligands $\left(\mathrm{MDD}_{\mathrm{EF}^{-}} \mathrm{SO}_{4}{ }^{2-}, \mathrm{MDD}_{\mathrm{EF}}-\mathrm{MVAPP}, \mathrm{MDD}_{\mathrm{EF}^{-}}\right.$

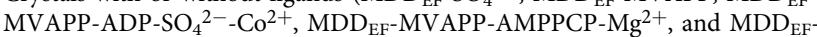
MVAPP-ADPBeF $3-\mathrm{Mg}^{2+}$ ) were obtained and frozen in liquid nitrogen.

Data collection and structure analysis. The diffraction data of an apo form of $\mathrm{MDD}_{\mathrm{EF}}\left(\mathrm{MDD}_{\mathrm{EF}^{-}}-\mathrm{SO}_{4}{ }^{2-}\right)$ and $\mathrm{MDD}_{\mathrm{EF}}$ soaked with ligands $\left(\mathrm{MDD}_{\mathrm{EF}}-\mathrm{MVAPP}\right.$, $\mathrm{MDD}_{\mathrm{EF}^{-}}$MVAPP-ADP-SO ${ }_{4}^{2-}-\mathrm{Co}^{2+}$ and $\mathrm{MDD}_{\mathrm{EF}^{-}}-\mathrm{MVAPP}-\mathrm{ADPBeF}_{3}-\mathrm{Mg}^{2+}$ ) were collected at the 23-ID-B and 23-ID-D beamline at Advanced Photon Source (APS) at Argonne National Laboratory in Chicago. Diffraction data of two ligandbound $\mathrm{MDD}_{\mathrm{EF}}, \mathrm{MDD}_{\mathrm{EF}^{-}}$MVAPP-AMPPCP- $\mathrm{Mg}^{2}-$ and $\mathrm{MDD}_{\mathrm{EF}}-\mathrm{MVAPP}-\mathrm{ADP}$ $\mathrm{SO}_{4}{ }^{2-}-\mathrm{Co}^{2+}$ (for cobalt anomalous signal data) were collected on the home-source $\mathrm{X}$-ray diffraction equipment (Purdue University Macromolecular Crystallography Facility). The HKL2000 software was used for space group determination, data integration, data reduction and data scaling ${ }^{54}$, and after data processing, a scalepacked reflection file (.sca) was generated. The software in CCP4, scalepack2mtz, was then used to convert the scalepack reflection file (.sca) to an MTZ format (.mtz) with R-free flag assigned (5-5.5\% $)^{55}$.

The program phenix.phaser was used to estimate the phases based on the molecular replacement method ${ }^{56}$, using the previous deposited $\mathrm{MDD}_{\mathrm{EF}^{-}}$ATP structure $(5 \mathrm{~V} 2 \mathrm{~L})$ as a search model. One solution was found with rotation function log-likelihood gain (LLG) $>0$ and translation function $Z$-score $(T F Z)>8$. Structure refinement was performed using phenix.refine ${ }^{56}$. Model geometry (XYZ coordinates), atomic positions (Real-space), and atomic B-factors (individual Bfactors) were refined, and models were manually examined in the graphical program $\operatorname{Coot}^{57}$ based on the electron density map $\left(2 F_{\mathrm{o}}-F_{\mathrm{c}}\right)$ and the difference map $\left(F_{\mathrm{o}}-F_{\mathrm{c}}\right)$. The simulated-annealing (Cartesian) option was employed in the first few refinement runs. The crystallographic information file (.cif) and the PDB format file (.pdb) of ligands (ADP, AMPPCP, MVAPP, $\mathrm{Co}^{2+}, \mathrm{BeF}_{3}{ }^{-}$) were generated using the program phenix.eLBOW ${ }^{56}$. After a few runs of structure refinement without ligands, ligands were manually placed and fitted into the weighted difference electron density maps $\left(F_{o}-F_{c}\right)$ in $\operatorname{Coot}^{57}$. Ligand-omit maps were generated using the phenix.composit_omit_map software for evaluating structural models of ligands. Each ligand-omit map and its corresponding structure were depicted in pymol ${ }^{58}$. Target function optimization (Optimize X-ray/ stereochemistry weight, Optimize X-ray/ADP weight) was also chosen for optimizing the weight between the X-ray data and the structural model. Water molecules were built and inspected in Coot.

Isothermal titration calorimetry experiments. The preparation of TEV-treated K187A was described above. The protein solution was dialyzed against buffer which is the same as used in the enzymatic reactions described previously $(100 \mathrm{mM}$ HEPES, pH 7, $100 \mathrm{mM} \mathrm{KCl}$, and $10 \mathrm{mM} \mathrm{MgCl}_{2}$ ). All the buffer solutions in ITC experiments were filtered through a $0.45 \mu \mathrm{M}$ filter and degassed for $1 \mathrm{~h}$ at room temperature. The protein concentration was adjusted to $100 \mu \mathrm{M}(260 \mu \mathrm{l})$. Each ligand (MVAPP, ATP, and ATP $\gamma \mathrm{S}$ ) was prepared in the same dialysis buffer to avoid buffer mismatch. The concentration of each titrant was optimized in different experiments based on the experimental designs simulated using the MicroCal Origin 7.0 software package, and the final concentration of each ligand was adjusted appropriately. The ITC instrument, MicroCal iTC200, was employed for isothermal titrations in this study and the reference cell was filled with $\mathrm{ddH}_{2} \mathrm{O}$ containing $0.01 \%$ sodium azide. The experimental temperature was set at $25^{\circ} \mathrm{C}$. Each experimental profile was composed of the addition of an initial aliquot of 0.4 $\mu \mathrm{l}$, followed by 22 aliquots of $1.8 \mu \mathrm{l}$ of the substrate or ligand solution. The time interval between two consecutive injections was $180 \mathrm{~s}$. The data were further processed with NITPIC ${ }^{59}$ and analyzed using a one-site model in SEDPHAT ${ }^{60}$ Figures were generated using GUSSI in SEDPHAT. 
Reporting summary. Further information on research design is available in the Nature Research Reporting Summary linked to this article.

\section{Data availability}

The X-ray data and corresponding atomic coordinates of $\mathrm{MDD}_{\mathrm{EF}}$ at unbound and different bound states $\left(\mathrm{MDD}_{\mathrm{EF}}-\mathrm{SO}_{4}{ }^{2-}: 6 \mathrm{E} 2 \mathrm{~S} ; \mathrm{MDD}_{\mathrm{FF}}-\mathrm{MVAPP}: 6 \mathrm{E} 2 \mathrm{~T} ; \mathrm{MDD}_{\mathrm{EF}}-\mathrm{MVAPP}-\mathrm{AMPPCP}-\right.$ $\mathrm{Mg}^{2+}: 6 \mathrm{E} 2 \mathrm{U} ; \mathrm{MDD}_{\mathrm{EF}}-\mathrm{MVAPP}-\mathrm{ADPBeF}_{3}-\mathrm{Mg}^{2+}: 6 \mathrm{E} 2 \mathrm{~V}$ ) and data for cobalt anomalous dispersion experiments (synchrotron data for $\mathrm{MDD}_{\mathrm{EF}} \mathrm{MVAPP}-\mathrm{ADP}-\mathrm{SO}_{4}{ }^{2-}-\mathrm{Co}^{2+}: 6 \mathrm{E} 2 \mathrm{~W}$; home-source data for $\mathrm{MDD}_{\mathrm{EF}}-\mathrm{MVAPP}-\mathrm{ADP}-\mathrm{SO}_{4}{ }^{2-}{ }^{2-} \mathrm{Co}^{2+}: 6 \mathrm{E} 2 \mathrm{Y}$ ) have been deposited in the Protein Data Bank. Source data are provided with this paper.

Received: 17 August 2019; Accepted: 30 June 2020;

Published online: 07 August 2020

\section{References}

1. Buhaescu, I. \& Izzedine, H. Mevalonate pathway: a review of clinical and therapeutical implications. Clin. Biochem. 40, 575-584 (2007).

2. Goldstein, J. L. \& Brown, M. S. Regulation of the mevalonate pathway. Nature 343, 425-430 (1990).

3. Wilding, E. I. et al. Identification, evolution, and essentiality of the mevalonate pathway for isopentenyl diphosphate biosynthesis in gram-positive cocci. $J$. Bacteriol. 182, 4319-4327 (2000).

4. Uttley, A. H. C., Collins, C. H., Naidoo, J. \& George, R. C. Vancomycinresistant Enterococci. Lancet 1, 57-58 (1988).

5. Centers for Disease Control and Prevention. Threat Report 2013 (CDC, 2013).

6. O’Driscoll, T. \& Crank, C. W. Vancomycin-resistant enterococcal infections: epidemiology, clinical manifestations, and optimal management. Infect. Drug Resist. 8, 217-230 (2015)

7. Paulsen, I. T. et al. Role of mobile DNA in the evolution of vancomycinresistant Enterococcus faecalis. Science 299, 2071-2074 (2003).

8. Leclercq, R., Derlot, E., Duval, J. \& Courvalin, P. Plasmid-mediated resistance to vancomycin and teicoplanin in Enterococcus faecium. N. Engl. J. Med 319, 157-161 (1988).

9. Sundsfjord, A. \& Willems, R. Enterococcus research: recent developments and clinical challenges. Clin. Microbiol. Infect. 16, 525-526 (2010).

10. Arias, C. A. \& Murray, B. E. The rise of the Enterococcus: beyond vancomycin resistance. Nat. Rev. Microbiol. 10, 266-278 (2012).

11. Courvalin, P. Vancomycin resistance in gram-positive cocci. Clin. Infect. Dis. 42, S25-S34 (2006).

12. Vilhena, C. \& Bettencourt, A. Daptomycin: a review of properties, clinical use, drug delivery and resistance. Mini Rev. Med. Chem. 12, 202-209 (2012).

13. Burleson, B. S., Ritchie, D. J., Micek, S. T. \& Dunne, W. M. Enterococcus faecalis resistant to linezolid: case series and review of the literature. Pharmacotherapy 24, 1225-1231 (2004).

14. Barber, K. E., Smith, J. R., Raut, A. \& Rybak, M. J. Evaluation of tedizolid against Staphylococcus aureus and enterococci with reduced susceptibility to vancomycin, daptomycin or linezolid. J. Antimicrob. Chemother. 71, 152-155 (2016).

15. Ramachandran, C. K. \& Shah, S. N. Decarboxylation of mevalonate pyrophosphate is one rate-limiting step in hepatic cholesterol synthesis in suckling and weaned rats. Biochem. Biophys. Res. Commun. 69, 42-47 (1976).

16. Andreassi, J. L., Dabovic, K. \& Leyh, T. S. Streptococcus pneumoniae isoprenoid biosynthesis is downregulated by diphosphomevalonate: an antimicrobial target. Biochemistry 43, 16461-16466 (2004).

17. Barta, M. L. et al. Crystal structures of Staphylococcus epidermidis mevalonate diphosphate decarboxylase bound to inhibitory analogs reveal new insight into substrate binding and catalysis. J. Biol. Chem. 286, 23900-23910 (2011).

18. Barta, M. L., McWhorter, W. J., Miziorko, H. M. \& Geisbrecht, B. V. Structural basis for nucleotide binding and reaction catalysis in mevalonate diphosphate decarboxylase. Biochemistry 51, 5611-5621 (2012).

19. Voynova, N. E. et al. Human mevalonate diphosphate decarboxylase: characterization, investigation of the mevalonate diphosphate binding site, and crystal structure. Arch. Biochem. Biophys. 480, 58-67 (2008).

20. Dhepaganon, S., Magrath, J. \& Abeles, R. H. Mechanism of mevalonate pyrophosphate decarboxylase-evidence for A carbocationic transition-state. Biochemistry 33, 13355-13362 (1994).

21. Nave, J. F., d'Orchymont, H., Ducep, J. B., Piriou, F. \& Jung, M. J. Mechanism of the inhibition of cholesterol biosynthesis by 6 -fluoromevalonate. Biochem. J. 227, 247-254 (1985).

22. Lombard, J. \& Moreira, D. Origins and early evolution of the mevalonate pathway of isoprenoid biosynthesis in the three domains of life. Mol. Biol. Evol. 28, 87-99 (2011).

23. Gschwend, D. A., Sirawaraporn, W., Santi, D. V. \& Kuntz, I. D. Specificity in structure-based drug design: identification of a novel, selective inhibitor of Pneumocystis carinii dihydrofolate reductase. Proteins 29, 59-67 (1997).
24. Chen, C. L., Mermoud, J. C., Paul, L. N., Steussy, C. N. \& Stauffacher, C. V. Mevalonate 5-diphosphate mediates ATP binding to the mevalonate diphosphate decarboxylase from the bacterial pathogen. J. Biol. Chem. 292, 21340-21351 (2017)

25. Jabalquinto, A. M. \& Cardemil, E. Substrate binding order in mevalonate 5 diphosphate decarboxylase from chicken liver. Biochim. Biophys. Acta 996, 257-259 (1989)

26. Bloch, K., Chaykin, S., Phillips, A. H. \& De Waard, A. Mevalonic acid pyrophosphate and isopentenylpyrophosphate. J. Biol. Chem. 234, 2595-2604 (1959).

27. Krepkiy, D. \& Miziorko, H. M. Identification of active site residues in mevalonate diphosphate decarboxylase: Implications for a family of phosphotransferases. Protein Sci. 13, 1875-1881 (2004).

28. Motoyama, K. et al. A single amino acid mutation converts (R)-5diphosphomevalonate decarboxylase into a kinase. J. Biol. Chem. 292, 2457-2469 (2017)

29. Jabalquinto, A. M. \& Cardemil, E. Kinetic effects of ATP, divalent metal-ions and $\mathrm{pH}$ on chicken liver mevalonate 5-diphosphate decarboxylase. Biochim. Biophys. Acta 916, 172-178 (1987).

30. WHO. Antimicrobial Resistance: Global Report on Surveillance 2014 1-257 (WHO, 2014).

31. Weigel, L. M. et al. Genetic analysis of a high-level vancomycin-resistant isolate of Staphylococcus aureus. Science 302, 1569-1571 (2003).

32. Byres, E., Alphey, M. S., Smith, T. K. \& Hunter, W. N. Crystal structures of Trypanosoma brucei and Staphylococcus aureus mevalonate diphosphate decarboxylase inform on the determinants of specificity and reactivity. J. Mol. Biol. 371, 540-553 (2007).

33. Xu, Y. W., Moréra, S., Janin, J. \& Cherfils, J. AlF3 mimics the transition state of protein phosphorylation in the crystal structure of nucleoside diphosphate kinase and MgADP. Proc. Natl. Acad. Sci. USA 94, 3579-3583 (1997).

34. Matte, A., Tari, L. W. \& Delbaere, L. T. How do kinases transfer phosphoryl groups? Structure 6, 413-419 (1998)

35. Michihara, A., Akasaki, K., Yamori, Y. \& Tsuji, H. Purification and characterization of mouse mevalonate pyrophosphate decarboxylase. Biol. Pharm. Bull. 25, 302-306 (2002).

36. Yang, C., Pflugrath, J. W., Courville, D. A., Stence, C. N. \& Ferrara, J. D. Away from the edge: SAD phasing from the sulfur anomalous signal measured inhouse with chromium radiation. Acta Crystallogr. Sect. D Biol. Crystallogr. 59 1943-1957 (2003).

37. Thomas, S. T., Louie, G. V., Lubin, J. W., Lundblad, V. \& Noel, J. P. Substrate specificity and engineering of mevalonate 5-phosphate decarboxylase. ACS Chem. Biol. 14, 1767-1779 (2019).

38. Carrera, A. C., Alexandrov, K. \& Roberts, T. M. The conserved lysine of the catalytic domain of protein-kinases is actively involved in the phosphotransfer reaction and not required for anchoring ATP. Proc. Natl. Acad. Sci. USA 90 442-446 (1993)

39. Mildvan, A. S. Mechanisms of signaling and related enzymes. Proteins Struct. Funct. Genet. 29, 401-416 (1997).

40. Qiu, Y. G., Gao, J. B., Guo, F., Qiao, Y. Q. \& Li, D. Mutation and inhibition studies of mevalonate 5-diphosphate decarboxylase. Bioorg. Med. Chem. Lett. 17, 6164-6168 (2007)

41. Jelesarov, I. \& Bosshard, H. R. Isothermal titration calorimetry and differential scanning calorimetry as complementary tools to investigate the energetics of biomolecular recognition. J. Mol. Recognit. 12, 3-18 (1999).

42. Adams, J. A. Kinetic and catalytic mechanisms of protein kinases. Chem. Rev. 101, 2271-2290 (2001).

43. Hahn, T., Shmueli, U., Wilson, A. J. C. \& International Union of Crystallography. International Tables for Crystallography (D. Reidel Pub. Co., Dordrecht, 1984).

44. Gurusaran, M., Shankar, M., Nagarajan, R., Helliwell, J. R. \& Sekar, K. Do we see what we should see? Describing non-covalent interactions in protein structures including precision. IUCrJ 1, 74-81 (2014).

45. McClory, J., Hui, C., Zhang, J. \& Huang, M. The phosphorylation mechanism of mevalonate diphosphate decarboxylase: a QM/MM study. Org. Biomol. Chem. 17, 2423-2431 (2019).

46. Wang, Z. \& Cole, P. A. Catalytic mechanisms and regulation of protein kinases. Methods Enzymol. 548, 1-21 (2014)

47. Alberty, R. A., Smith, R. M. \& Bock, R. M. The apparent ionization constants of the adenosinephosphates and related compounds. J. Biol. Chem. 193, 425-434 (1951).

48. Michihara, A., Sawamura, M., Nara, Y., Ikeda, K. \& Yamori, Y. Purification and characterization of two mevalonate pyrophosphate decarboxylases from rat liver: a novel molecular species of $37 \mathrm{kDa}$. J. Biochem .122, 647-654 (1997).

49. Alvear, M., Jabalquinto, A. M., Eyzaguirre, J. \& Cardemil, E. Purification and characterization of avian liver mevalonate-5-pyrophosphate decarboxylase. Biochemistry 21, 4646-4650 (1982).

50. Zheng, L., Baumann, U. \& Reymond, J. L. An efficient one-step site-directed and site-saturation mutagenesis protocol. Nucleic Acids Res. 32, el15 (2004). 
51. Mermoud, J., Stauffacher, Cynthia V., Charbonneau, Harry, \& Friedman Alan. Purdue University (2009).

52. Sievers, F. et al. Fast, scalable generation of high-quality protein multiple sequence alignments using Clustal Omega. Mol. Syst. Biol. 7, 539 (2011).

53. Robert, X. \& Gouet, P. Deciphering key features in protein structures with the new ENDscript server. Nucleic Acids Res. 42, W320-W324 (2014).

54. Otwinowski, Z. \& Minor, W. Processing of X-ray diffraction data collected in oscillation mode. Meth. Enzymol. 276, 307-326 (1997).

55. Winn, M. D. et al. Overview of the CCP4 suite and current developments. Acta Crystallogr. D Biol. Crystallogr. 67, 235-242 (2011).

56. Adams, P. D. et al. PHENIX: a comprehensive Python-based system for macromolecular structure solution. Acta Crystallogr. D Biol. Crystallogr. 66 213-221 (2010).

57. Emsley, P. \& Cowtan, K. Coot: model-building tools for molecular graphics. Acta Crystallogr. D Biol. Crystallogr. 60, 2126-2132 (2004).

58. Schro"dinger, L. L. C. The PyMOL Molecular Graphics System 1.5.0.4 ed. (2015).

59. Keller, S. et al. High-precision isothermal titration calorimetry with automated peak-shape analysis. Anal. Chem. 84, 5066-5073 (2012).

60. Houtman, J. C. D. et al. Studying multisite binary and ternary protein interactions by global analysis of isothermal titration calorimetry data in SEDPHAT: Application to adaptor protein complexes in cell signaling. Protein Sci. 16, 30-42 (2007)

61. Hutchinson, E. G. \& Thornton, J. M. PROMOTIF-a program to identify and analyze structural motifs in proteins. Protein Sci. 5, 212-220 (1996).

\section{Acknowledgements}

We thank Tim Schmidt (Macromolecule Crystallography X-Ray Diffraction Lab, Purdue University) for his help with X-ray data collection and the Advanced Photon Source (APS) at Argonne National Laboratory in Chicago for access to the beamlines of 23-ID-B and 23-ID-D.GM/CA@APS has been funded in whole or in part with Federal funds from the National Cancer Institute (ACB-12002) and the National Institute of General Medical Sciences (AGM-12006). This research used resources of the Advanced Photon Source, a U.S. Department of Energy (DOE) Office of Science User Facility operated for the DOE Office of Science by Argonne National Laboratory under Contract No. DE-AC02$06 \mathrm{CH} 11357$. The Eiger $16 \mathrm{M}$ detector was funded by an NIH-Office of Research Infrastructure Programs, High-End Instrumentation Grant (1S10OD012289-01A1). We also gratefully acknowledge use of the Macromolecular Crystallography Shared Resource with support from the Purdue Center for Cancer Research and NIH grant P30 CA023168.

\section{Author contributions}

C.-L.C. and C.V.S. designed the experiments. J.C.M cloned the MDD protein. C.-L.C. purified the K187A mutant and the wild-type $\mathrm{MDD}_{\mathrm{EF}}$ proteins for study on enzymology, thermodynamics, and crystallization. C.-L.C. analyzed data. L.N.P. designed and performed the ITC experiments. C.N.S. assisted in reviewing the MDD X-ray crystal structures. C.-L.C. and C.V.S. collaborated in writing the article.

\section{Competing interests}

The authors declare no competing interests.

\section{Additional information}

Supplementary information is available for this paper at https://doi.org/10.1038/s41467020-17733-0.

Correspondence and requests for materials should be addressed to C.V.S.

Peer review information: Nature Communications thanks Hisashi Hemmi and Bernhard Loll for their contribution to the peer review of this work. Peer reviewer reports are available.

Reprints and permission information is available at http://www.nature.com/reprints

Publisher's note Springer Nature remains neutral with regard to jurisdictional claims in published maps and institutional affiliations.

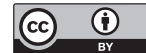

Open Access This article is licensed under a Creative Commons Attribution 4.0 International License, which permits use, sharing adaptation, distribution and reproduction in any medium or format, as long as you give appropriate credit to the original author(s) and the source, provide a link to the Creative Commons license, and indicate if changes were made. The images or other third party material in this article are included in the article's Creative Commons license, unles indicated otherwise in a credit line to the material. If material is not included in the article's Creative Commons license and your intended use is not permitted by statutory regulation or exceeds the permitted use, you will need to obtain permission directly from the copyright holder. To view a copy of this license, visit http://creativecommons.org/ licenses/by/4.0/

(C) The Author(s) 2020 